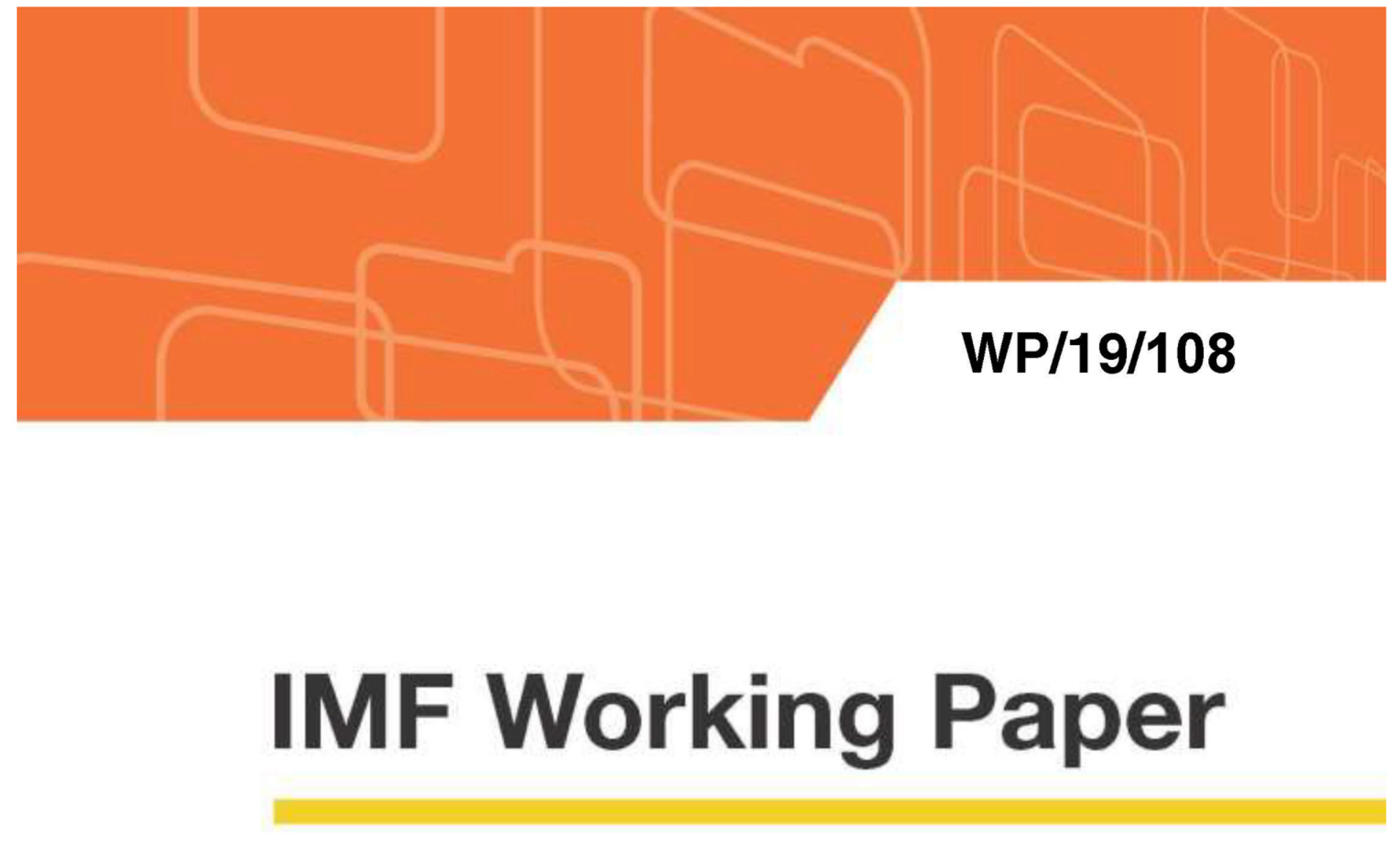

\title{
Rethinking Fiscal Policy in Oil-Exporting Countries
}

by Tokhir Mirzoev and Ling Zhu

IMF Working Papers describe research in progress by the author(s) and are published to elicit comments and to encourage debate. The views expressed in IMF Working Papers are those of the author(s) and do not necessarily represent the views of the IMF, its Executive Board, or IMF management. 


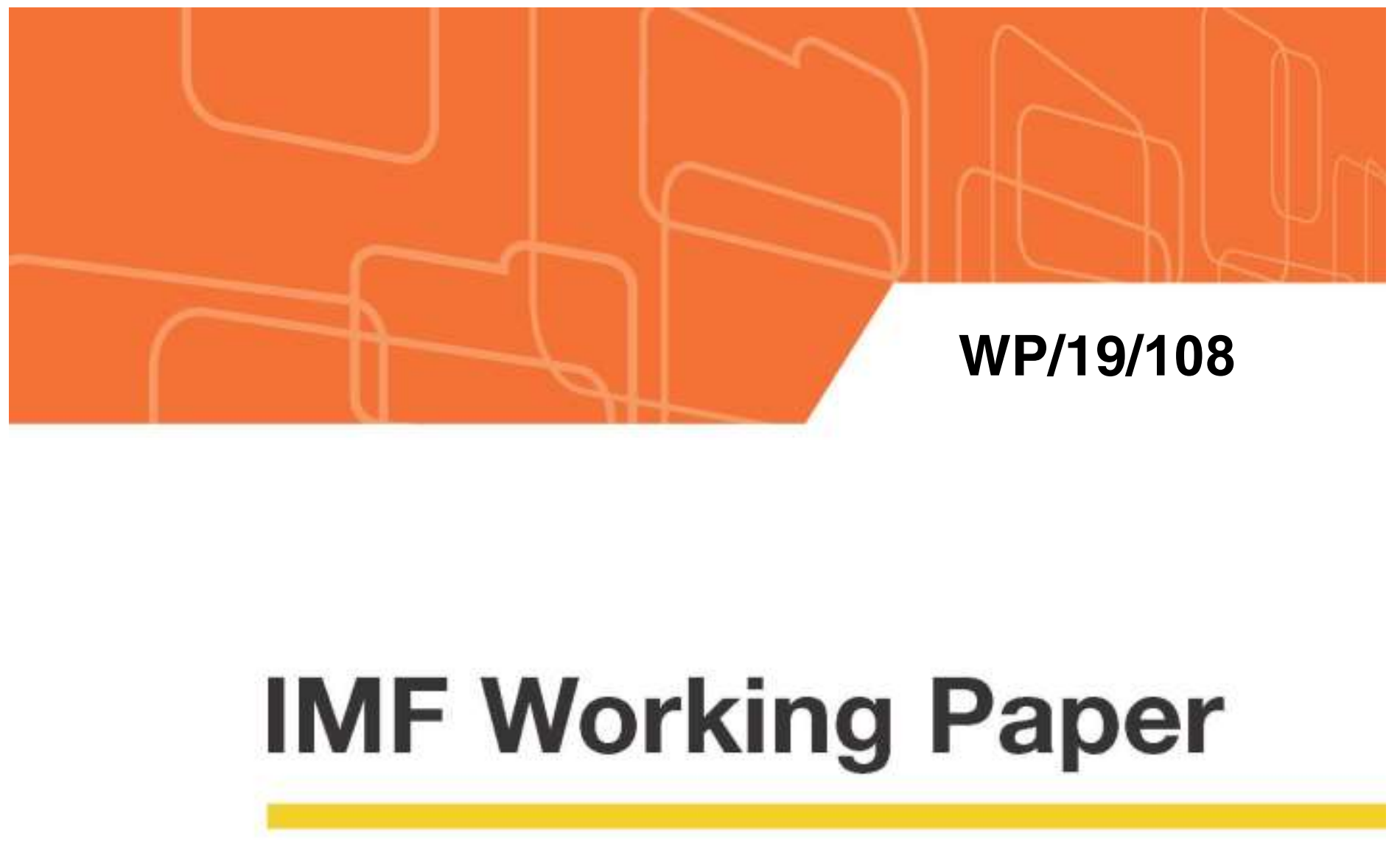

Rethinking Fiscal Policy in Oil-Exporting Countries

by Tokhir Mirzoev and Ling Zhu

IMF Working Papers describe research in progress by the author(s) and are published to elicit comments and to encourage debate. The views expressed in IMF Working Papers are those of the author(s) and do not necessarily represent the views of the IMF, its Executive Board, or IMF management.

I NTER N ATION AL MONETARY FUND 


\title{
IMF Working Paper
}

Middle East and Central Asia Department

\section{Rethinking Fiscal Policy in Oil-Exporting Countries ${ }^{1}$}

\section{Prepared by Tokhir Mirzoev and Ling Zhu}

Authorized for distribution by Timothy Callen

May 2019

\section{IMF Working Papers describe research in progress by the author(s) and are published to} elicit comments and to encourage debate. The views expressed in IMF Working Papers are those of the author(s) and do not necessarily represent the views of the IMF, its Executive Board, or IMF management.

\begin{abstract}
We examine the existing fiscal policy paradigm in commodity-exporting countries. First, we argue that its centerpiece - the permanent income hypothesis (PIH) - is not consistent with either intergenerational equity or long-term sustainability in the presence of uncertainty. Policies to achieve these goals need to be more prudent and better anchored than the PIH. Second, we point out the presence of a volatility tradeoff between government spending and wealth and re-assess long-held views on the appropriate fiscal anchors, the vice of procyclicality, and the (im)possibility of simultaneously smoothing consumption and ensuring intergenerational equity and sustainability. Finally, we propose what we call a prudent wealth stabilization policy that would be more consistent with long-term fiscal policy goals, yet relatively simple to implement and communicate.
\end{abstract}

JEL Classification Numbers: E62, H30, Q33

Keywords: Fiscal policy, oil exporters, permanent income hypothesis, fiscal rules

Authors’ E-Mail Addresses: tmirzoev@,imf.org, 1zhu@,imf.org

\footnotetext{
${ }^{1}$ We are thankful to Aasim Husain, Tim Callen, Natalia Tamirisa, Vitor Gaspar, Andrew Berg, Tobias Adrian, Abdelhak Senhadji, Felipe Zanna, Jason Harris, Divya Kirti, Athanasios Arvanitis, Hossein Samiei, Paulo Medas, Luc Eyraud, Victor Lledo, Mauricio Soto, Erik Lundback, Helene Poirson-Ward, Olivier Basdevant, John Hooley, and seminar participants in various departments of the IMF for constructive comments, useful suggestions, and productive discussions at various stages of the paper. Alexandra Panagiotakopoulou provided excellent editorial support. Remaining errors are ours.
} 


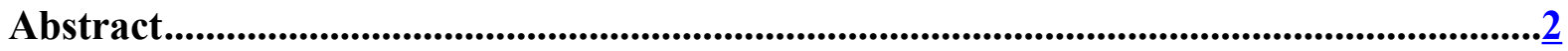

I. Introduction ......................................................................................................................................

II. Analytical Framework........................................................................................................................

III. PIH Under Uncertainty ..............................................................................................................11

A. Intuition ....................................................................................................11

A Tale of Two Extremes.....................................................................11

Understanding Non-stationarity …………………….............................12

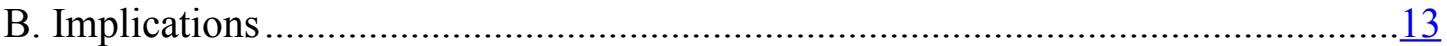

Long-term Sustainability ………………………………………….....

Intergenerational Equity...........................................................................13

IV. Hallmarks of Optimal Policy .................................................................................................15

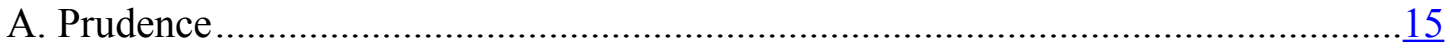

B. Anchoring .....................................................................................................17

V. Rethinking Fiscal Policy ………...............................................................................................20

A. Recognizing the Volatility Tradeoff ................................................................

B. Policy Implications .....................................................................................

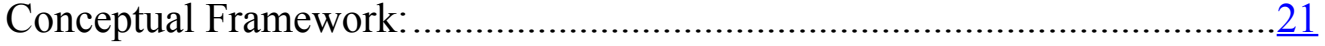

Fiscal Framework Design: .....................................................................

Fiscal Targets: ........................................................................................

C. Prudent Wealth Stabilization (PWS) Rule ...........................................................22

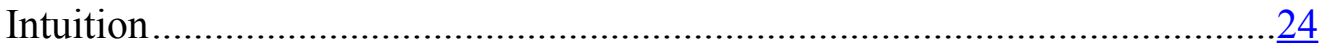

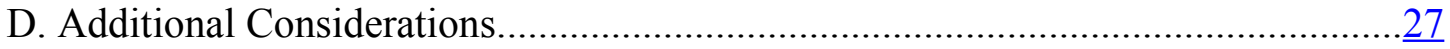

PWS Implementation Issues .................................................................

Public Investment...............................................................................

VI. Concluding Thoughts .........................................................................................................

VII. References .......................................................................................................................................39

\section{Figures}

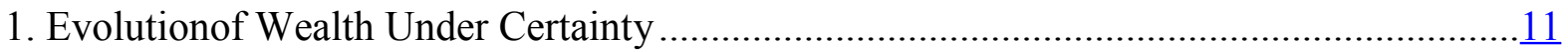

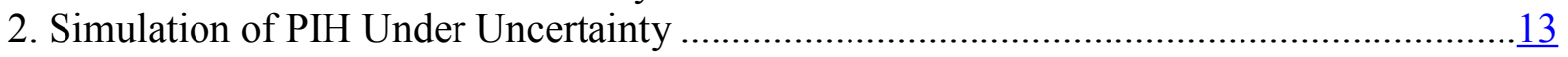

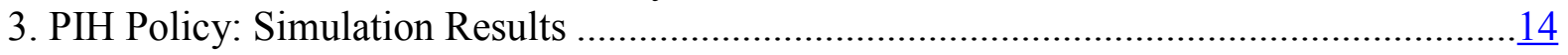

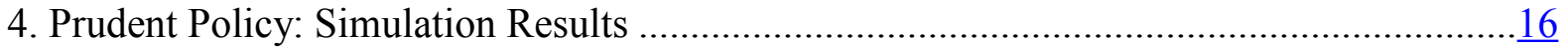

5. Wealth-Anchoring Policy: Simulation Results ............................................................... 19

6. Volatility Tradeoff: Extreme Stabilization Scenarios ......................................................20

7. Volatility Tradeoff in PWS Policy..............................................................................24

8. Prudent Wealth Stabilization (PWS) Policy: Simulation Results.......................................25

9. Statistical Properties of Wealth and Government Spending under PWS and PIH Rules:

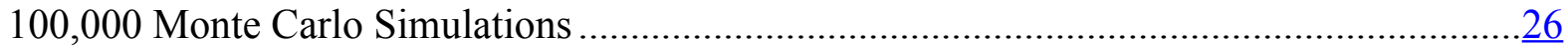




\section{Appendixes}

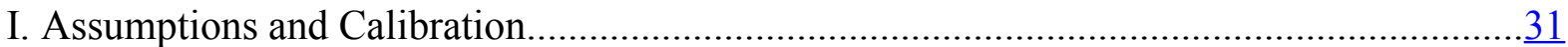

II. Non-stationarity Under PIH: Illustrative Example..................................................... $\underline{32}$

III. Procedure for Optimal Policy Solution .................................................................. $\frac{34}{37}$

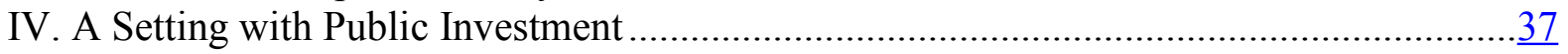


"We find it important to feature uncertainty rather than to diminish its importance."

(Brock and Hansen, 2018, p. 3)

\section{INTRODUCTION}

1. The centerpiece of the prevailing fiscal policy paradigm in resource-rich countries is the permanent income hypothesis (PIH), which is often used as a guidepost for fiscal policy to smooth government spending and ensure long-term sustainability and intergenerational equity. ${ }^{2}$ In its most common application, the benchmark is taken to be the real annuity value of a country's estimated net resource wealth: subsoil resources and financial assets accumulated from resource extraction. In recent years, the PIH framework has been extended to also accommodate the role of public investment, particularly in countries with large infrastructure needs. ${ }^{3}$ Over the past decade or so, PIH has been a popular theme in fiscal policy discussions.

2. In a world without shocks, the PIH is the best possible fiscal strategy in resource-rich countries, and is analogous to the spirit of Hartwick's rule: a society that invests income from exhaustible resources in productive capital would be able to maintain a constant stream of consumption indefinitely. ${ }^{4}$ Hartwick's "zero net investment rule"-i.e. when resource extraction is offset by investment into productive capital — was shown to generate the highest possible sustainable level of consumption, similar to the predictions of the PIH (Friedman, 1957).

3. But, as it often goes, the fine print accompanying these findings has been set aside in policy applications. The most crucial caveat underlying the optimality of both Hartwick's rule and the PIH is their ability to preserve wealth in the absence of shocks. ${ }^{5}$ Preserving wealth in a world of certainty is straightforward, but there is no reason to assume wealth to remain unchanged when it is affected by fluctuations in, for example, commodity prices and

\footnotetext{
${ }^{2}$ Davis and others (2003) and IMF (2012 and 2015) provide comprehensive discussions of fiscal frameworks in oil exporting countries from both policy and operational perspectives.

${ }^{3}$ See, for example, Berg et al. (2012), Araujo et al. (2016), and IMF $(2012,2015)$ among others. As discussed in Section V.D, these extensions, despite somewhat different predictions for budget and external deficits, have similar long-term sustainability and intergenerational equity predictions as the standard PIH model.

${ }^{4}$ The rule was elaborated in a series of papers by John Hartwick (1977, 1978a, 1978b) in the context of a broader literature which appeared in the wake of the oil price shocks and focused on sustainability and intergenerational equity (in contrast to the optimal rate of resource extraction studied by Hotelling,1931). The main difference between Hartwick's framework and PIH is the focus on accumulation of physical rather than financial capital. This difference is critical for the discussion of stationarity in the following sections.

${ }^{5}$ Parallels with Friedman's PIH may be the reason for insufficient emphasis on wealth preservation in recent studies. Fiscal policy application of PIH has focused on how much to consume given some notion of an estimated permanent income (which is assumed to be constant). By contrast, Hartwick's theory is more about how to ensure the permanence of income out of exhaustible resources. This subtle but important distinction becomes crucial when one ponders the effects of uncertainty (see section III).
} 
interest rates. And when wealth is not maintained intact, the optimality of PIH is no longer guaranteed.

4. To motivate the discussion that follows, consider a generation entrusted with a financial endowment of $\$ 100$, earning a five percent annual dividend. Under PIH, this generation should consume the dividend income from this endowment (\$5) so that the principal can be preserved for their descendants. Now suppose that as a result of some one-off misfortune, a part of the principal endowment, say $\$ 20$, is lost. The common application of PIH would set post-shock consumption to $\$ 4$-five percent of the remaining $\$ 80$. Is such a policy sustainable and consistent with intergenerational equity?

5. Two observations arise from this example. First, although following PIH may be a sensible course of action from the present generation's perspective, if future generations had a say, they might argue for larger savings to restore wealth to its initial level. There is no naturally optimal level at which wealth should be maintained and evaluating these alternatives requires a clear metric by which to measure intergenerational equity. Second, had the saving policy of the present generation reflected the imaginary voice of the descendants and tried to restore wealth in response to the shock, wealth would have the statistical property of mean reversion. But PIH effectively seeks to preserve the post-shock value of wealth, making the effects of even a transitory shock on wealth permanent. Such a policy would cause wealth to be a random walk. And if spending is anchored to wealth, it too would be nonstationary. These issues are somewhat submerged in the common application of PIH.

6. What constitutes an equitable distribution of resources across generations is as much an ethical/philosophical as it is an economic question. Fortunately, a sizable literature has already examined this issue. Unfortunately, none of the concepts stemming from this literature are universally accepted or fully satisfactory. ${ }^{6}$ Modern welfare economics has gravitated toward Ramsey's utilitarian framework, where intergenerational equity is achieved by maximizing a discounted sum of expected utilities of all generations (Ramsey, 1928). This metric will be used in this paper-mostly for the lack of a better alternative - while recognizing the need for a better notion of what is equitable across generations. ${ }^{7}$

7. Similarly, long-term sustainability is usually defined in general terms, such as the ability to sustain the current level of consumption. Often, this been taken to mean that

\footnotetext{
${ }^{6}$ Arrow (1973) and Solow (1974), for example, have studied Rawls' principle of maximizing the utility of the least well-off generation (see Rawls, 1971). There are several awkward implications of such a principle, notably a strong bias toward current generations.

${ }^{7}$ The use of discounting and the assumption that all generations will have the same utility function are some of the problematic features of the utilitarian approach. Ramsey considered discounting future utilities to be ethically inappropriate. In the "cake eating problem," studied by Koopmans $(1973,1974)$, discounting leads to overconsumption by the present generation thus advancing, in his words, the "doomsday." This point is particularly pertinent in environmental economics (Ploeg, 2014 and Brock and Hansen, 2018).
} 
consumption must ex ante satisfy the life-time budget constraint. However, this criterion alone is not sufficient to ensure long-term sustainability, especially in the presence of significant income uncertainty. A more informed evaluation of long-term sustainability must involve a probabilistic assessment of long-term wealth (permanent income) and consumption, as well as the associated tail risks. ${ }^{8}$

8. On this basis, after laying out the analytical framework in section II, section III discusses the implications of following the PIH in a world with oil price shocks. Government spending is smoothed in the short term because it is set to a small fraction of wealth. But commodity price shocks do not disappear - they are simply passed onto government saving and wealth. And short-term smoothing masks high long-term volatility as both wealth and spending are non-stationarity. Put differently, consumption smoothing under the PIH simply transfers risk to future generations whose well-being can significantly differ from that of the present one. This makes PIH inconsistent with either intergenerational equity or long-term sustainability.

9. Section IV employs numerical methods to characterize the optimally prudent policy from the perspective of intergenerational equity. It calls for a precautionary premium - additional savings to compensate future generations for the risks they face. This amounts to aiming at a higher expected level of wealth at the time of resource exhaustion. Initial generations must bear the burden of these additional savings so that subsequent generations could consume more relative to $\mathrm{PIH}$ - a pattern that mirrors the relative risk faced by these cohorts. Interestingly, higher consumption is achieved well before the exhaustion of natural resources because initial savings generate additional dividend income, and the precautionary saving motive weakens over time as residual risks associated with oil price volatility subside with the nearing of resource exhaustion.

10. Ensuring intergenerational equity does not guarantee long-term sustainability. Even when generations' collective utilities are maximized, wealth remains non-stationary, requiring wealth-stabilizing policies to make the framework better anchored. Implementing the latter sheds light on another key message of this paper: there is a volatility tradeoff - a choice between smoothing consumption and stabilizing wealth in oil-exporting countries. Anchoring wealth requires higher short-term volatility of government spending because it must partially offset shocks. Contrariwise, prioritizing consumption smoothing, as under $\mathrm{PIH}$, makes wealth less stable.

11. Section $\mathrm{V}$ discusses the importance of this tradeoff and frames long-term fiscal policy analysis through its lenses. We propose to view long-term fiscal strategy as that of balancing smoothing expenditure, intergenerational equity and long-term sustainability, and to anchor this strategy with a long-term target for post-oil wealth supported by medium-term

\footnotetext{
${ }^{8}$ Blanchard and Das (2017) discuss the probabilistic approach to assessing debt sustainability.
} 
frameworks aimed at increasing wealth toward that target. The common perception of procyclicality as a policy vice is also reconsidered given its benefits in stabilizing wealth.

12. As the final contribution, we propose an alternative to the $\mathrm{PIH}$ - prudent wealth stabilization policy. It replicates important features of the optimal policy-balancing the volatility tradeoff, improving intergenerational equity with precautionary savings and ensuring long-term sustainability with better anchoring - while being simple, intuitive, and relatively easy to implement.

\section{ANALYTICAL FrameWORK}

13. Setting. Consider an oil exporting economy, whose government's income at every period $t$ consists of oil revenue $\left(y_{t}\right)$, non-oil income from taxes or fees $\left(y_{t}^{n}\right)$, and interest income from investing last period's financial wealth $\left(a_{t-1}\right)$ at an exogenously determined world interest rate $\left(r_{t}\right)$. The end-period net present value (NPV) of total wealth $\left(w_{t}\right)$ of such a government can be represented as a sum of financial wealth $a_{t}$ and the NPVs of lifetime non-oil income $\left(Y_{t}^{n}\right)$ and subsoil oil wealth $\left(Q_{t}\right)$.

$$
w_{t}=a_{t}+Y_{t}^{n}+Q_{t}
$$

Every period, the government spends some part of its revenue and wealth $\left(g_{t}\right)$. Thus, end-of-period financial wealth evolves as follows:

$$
a_{t}=\left(1+r_{t-1}\right) a_{t-1}+y_{t}+y_{t}^{n}-g_{t}
$$

The last two components of wealth in (1) are the expected sums of the respective income streams discounted at the world interest rate:

$$
\begin{gathered}
Y_{t}^{n}=E_{t} \sum_{i=1}^{\infty} \frac{y_{t+i}^{n}}{\left(1+r_{t+i}\right)^{i}} \\
Q_{t}=E_{t} \sum_{i=1}^{T-t} \frac{y_{t+i}}{\left(1+r_{t+i}\right)^{i}}
\end{gathered}
$$

Oil revenue is obtained by extracting $q_{t}$ barrels every period subject to a per-barrel $\operatorname{cost}\left(v_{t}\right)$ and selling it at the exogenously determined price $\left(p_{t}\right)$. Let $T$ denote the period of oil exhaustion. Oil revenue can be described as follows:

$$
\begin{cases}y_{t}=\left(p_{t}-v_{t}\right) q_{t}, & \text { for } t \leq T \\ y_{t}=0, & \text { for } t>T\end{cases}
$$


14. Uncertainty and simplification. To simplify the analysis, the oil price is assumed to be the only source of uncertainty. It is assumed to follow an AR(1) process in logs:

$$
\log \left(p_{t}\right)=\mu+\rho \log \left(p_{t-1}\right)+\varepsilon_{t},
$$

where shocks $\varepsilon_{t}$ are iid with zero mean and normal distribution with a standard deviation $\sigma$.

Other potential sources of volatility - non-oil revenue, interest rate, cost of oil extraction, and annual oil output-are assumed to be constant $\left(r_{t}=r, y_{t}^{n}=y^{n}, v_{t}=v, q_{t}=q\right)$. While other shocks, such as interest rate fluctuations, have been omitted to keep the model simple and consistent with most other studies, they are highly relevant. Including these shocks would not affect our main arguments - wealth would remain non-stationary and its volatility will depend on the covariance between the oil price and interest rate shocks; and future generations would face even greater risk than earlier generations as long as the oil price shocks are not completely offset by interest rate shocks.

15. Wealth dynamics. Iteration of equations (3) and (4) forward allows us to express non-oil and oil wealth in recursive form:

$$
\begin{gathered}
Y_{t}^{n}=\left(1+r_{t-1}\right) Y_{t-1}^{n}-y_{t}^{n}, \\
Q_{t}=\left(1+r_{t-1}\right) Q_{t-1}-E_{t-1} y_{t}+\phi_{t}
\end{gathered}
$$

Equation (7) simply states that the present value of lifetime non-oil income increases at the rate of interest as the future revenue stream is discounted less, by a factor of $\left(1+r_{t-1}\right)$, and is reduced by the contemporaneous income $\left(y_{t}^{n}\right)$, which is added to financial wealth in equation (2). Similarly, the first term on right-hand-side of (8) indicates that the NPV of subsoil wealth increases at the rate of interest, because each unextracted barrel of oil is becoming worth more (discounted less) with the passage of time as its extraction period nears. At the same time, the previous period's expectation of current oil output is subtracted from the valuation when oil is extracted and sold. The actual realized revenue $\left(y_{t}\right)$ from this sale is added to financial wealth in equation (2). Finally, the last term:

$$
\phi_{t}=E_{t}\left(\sum_{i=1}^{T-t} \frac{y_{t+i}}{(1+r)^{i}}\right)-E_{t-1}\left(\sum_{i=1}^{T-t} \frac{y_{t+i}}{(1+r)^{i}}\right)
$$

captures the change in the expected discounted stream of future oil revenue, e.g. effected by oil price shocks. Combining equations (2) and (7)-(8) with (1) allows to formulate the law of motion for total wealth as follows:

$$
w_{t}=\left(1+r_{t-1}\right) w_{t-1}-g_{t}+\tilde{\phi}_{t}
$$


Thus, NPV of wealth can be interpreted as earning a gross rate of return $\left(1+r_{t-1}\right)$ regardless of whether it is invested in financial assets or below ground (due to lighter discounting). At the same time, consumption $\left(g_{t}\right)$ reduces wealth while $\tilde{\phi}_{t}$ represents the change in the expected value of present and future oil income streams between periods and summarizes the overall impact of uncertainty:

$$
\tilde{\phi}_{t}=y_{t}-E_{t-1} y_{t}+\phi_{t}=E_{t}\left(\sum_{i=0}^{T-t} \frac{y_{t+i}}{(1+r)^{i}}\right)-E_{t-1}\left(\sum_{i=0}^{T-t} \frac{y_{t+i}}{(1+r)^{i}}\right), t<T
$$

16. Preferences. Government is assumed to distribute funds to the population whose aggregate consumption is equal to government expenditure. Therefore, these terms are used interchangeably. Preferences are described by a von Neumann-Morgenstern instantaneous utility function $U_{t}=U\left(g_{t}\right)$ which is thrice continuously differentiable and satisfies the usual conditions $\left(U^{\prime}(\cdot)>0, U^{\prime \prime}(\cdot) \leq 0, U^{\prime \prime \prime}(\cdot)>0\right)$. Intergenerational equity is assumed to be consistent with the government maximizing the expected discounted sum of utilities of present and future generations:

$$
\operatorname{Max} E_{t} \sum_{i=0}^{\infty} \beta^{t+i} U\left(g_{t+i}\right)
$$

where $\beta$ is the discount factor which, for simplicity, is assumed to satisfy $\beta(1+r)=1$.

The government's task is to maximize (10) subject to the evolution of wealth (9).

Consistency with intergenerational equity is equivalent to equating expected marginal utilities of all generations:

$$
U^{\prime}\left(g_{t}\right)=\beta(1+r) E_{t} U^{\prime}\left(g_{t+i}\right), \forall i>0
$$

17. Calibration. For illustrative purposes, the model is calibrated to match the basic features of the United Arab Emirates' (UAE) economy (see Appendix I). Preferences are assumed to display constant relative risk aversion, or constant intergenerational inequality aversion in the terminology of van der Ploeg (2014). 


\section{PIH Under UnCERTAinty}

\section{A. Intuition}

\section{A Tale of Two Extremes}

18. In the absence of shocks, the optimality condition (11) reduces to equating government spending in each period: $g_{t}=g_{t-1}=g$. Because $\tilde{\phi}=0$ in equation (9), ensuring a constant level of consumption requires a saving policy that also maintains a constant level of wealth. This, in turn, implies a spending policy that skims off the return on wealth ( $g=r w)$ while maintaining its principal value intact (Figure 1). Skimming less would cause wealth to rise, benefiting future generations, while skimming more would

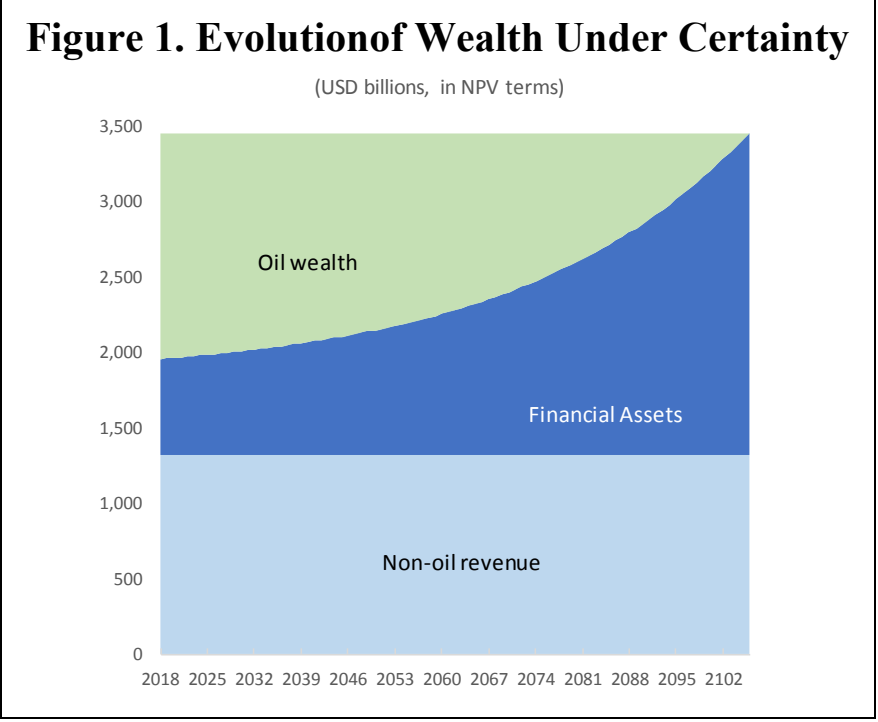

19. reduce its principal value. In this setting, $\mathrm{PIH}$ ensures both intergenerational equity and long-term sustainability.

20. The idyll of the insulated environment in Figure 1 changes dramatically in the presence of shocks. First, the duality of constant wealth and consumption, which made PIH optimal, is no longer possible. An oil price shock $\left(\tilde{\phi}_{t} \neq 0\right.$ in (9)(9)) will necessarily change either wealth or spending, or both, depending on how spending reacts to the shock. Second, under PIH, wealth becomes non-stationary as spending continues to skim off the returns on wealth regardless of the sign or magnitude of shocks:

$$
g_{t}=r w_{t-1}
$$

It can be interpreted as seeking to preserve the post-shock level of wealth after each oil price change - as if such changes would cease going forward - which makes the impact of shocks on wealth permanent. Therefore, wealth follows a random walk. The latter lays bare when equations (9) and (12) are combined:

$$
w_{t}=w_{t-1}+\tilde{\phi}_{t}
$$

In sum, a policy which ensures intergenerational equity and long-term sustainability in the absence of shocks, makes achieving these goals virtually impossible in an uncertain world. 


\section{Understanding Non-stationarity}

21. It is important to emphasize that wealth under PIH is non-stationary regardless of whether the oil price is stationary or not as long as the oil price is stochastic. ${ }^{9}$ This is not unique to the PIH framework and is a common feature in a large class of representative agent models. Students of international macroeconomics may recognize its semblance with a similar phenomenon in small open economy models à la Obstfeld and Rogoff (1995). ${ }^{10}$ It is of little consequence when the focus of analysis is on the short-run dynamics. But it becomes important when intertemporal redistribution issues come into play. For the same reason, nonstationarity of wealth is crucial when examining intergenerational equity and long-term sustainability.

22. Non-stationarity of the model in which the PIH is derived stems from the indeterminacy of its long-run equilibrium. To better understand the intuition behind it, consider Hartwick's framework, in which wealth is accumulated in physical capital rather than financial assets. In addition to the Euler equation (11) and the budget constraint (9), his framework involves cost minimization which also requires equating the marginal product of capital with the real interest rate. This pins down a unique equilibrium level of capital (under usual assumptions about the shape of the production function). Moreover, optimal capital is linked to the marginal rate of intertemporal substitution of consumption $\left(\frac{U^{\prime}\left(g_{t}\right)}{E_{t}\left[\beta U^{\prime}\left(g_{t+1}\right)\right]}\right)$ through the Euler equation. Thus, for any given interest rate, a negative shock to capital would raise its marginal product, prompt consumption growth to slow and investment to rise, so that capital would gravitate back to its optimal level.

23. By contrast, the link between wealth and the marginal rate of intertemporal substitution is absent in the PIH framework and precludes identifying a unique steady state. Any level of wealth will be consistent with the steady state as long as consumption follows (12). For convenience, the steady state is simply assumed to be equal to its initial (or, in practice, last period's) value. But it cannot be interpreted as a long-term value of wealth in the presence of shocks: every post-shock value is treated as a new long-term equilibrium. Because optimal consumption growth in (11) is independent of wealth, there is no reason for wealth to gravitate back to its initial value as capital does in Hartwick's framework.

\footnotetext{
${ }^{9}$ Appendix II illustrates how non-stationarity arises under transitory and permanent shocks.

${ }^{10}$ Net foreign assets are non-stationary in the standard small open economy model (see, for example, Schmitt-Grohe and Uribe (2003) and Ghironi, 2006, 2008).
} 


\section{B. Implications}

\section{Long-term Sustainability}

24. Figure 2 illustrates the behavior of government spending and wealth in a simulation with oil price shocks. PIH performs well in short-term smoothing of spending and reducing its procyclicality relative to the oil price. But this only serves to transfer volatility onto saving. And because each shock has a permanent effect on wealth, the latter declines precipitously following a series of negative oil price shocks (see also Figure 3, panel 3.1). While smoothed, consumption follows a similar pattern and is also non-stationary. The longterm volatility that is passed onto future generations in this setting would be larger for more volatile oil prices and longer resource horizons

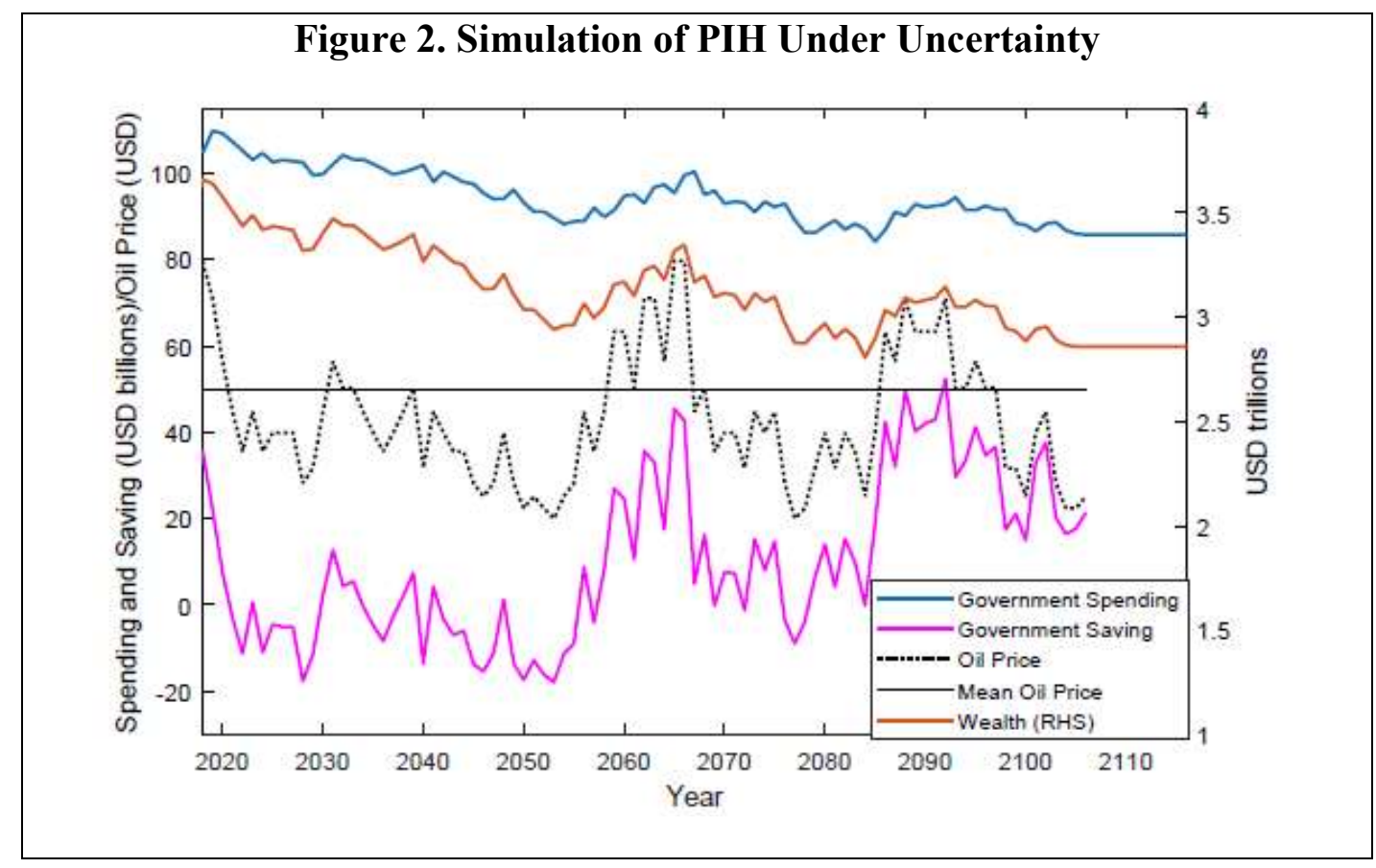

\section{Intergenerational Equity}

25. Is such a policy consistent with intergenerational equity? Monte Carlo simulations help gauge the uncertainty faced by future generations (Figure 3). Although the expectations of both wealth and consumption (as of the initial period) are similar to their starting values, the non-oil extracting generation faces significant risk when it comes to the levels of wealth it will actually inherit and consumption it will be able to afford. This mean-preserving spread means that PIH would be consistent with intergeneration equity only if cohorts are risk neutral. Under risk aversion, future generations are strictly worse off. 


\section{Figure 3. PIH Policy: Simulation Results}

\subsection{Wealth: 100,000 Oil Price Simulations}

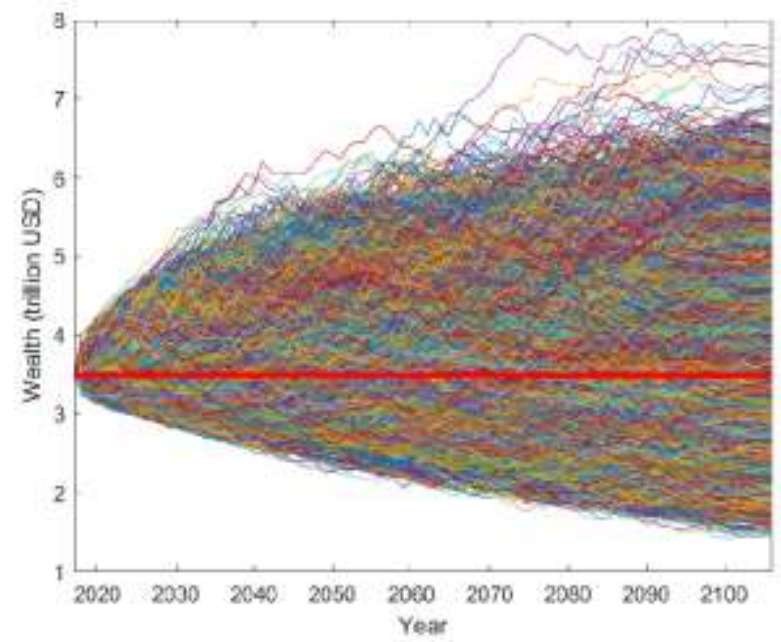

3.2 Distribution of Post-Oil Government Spending

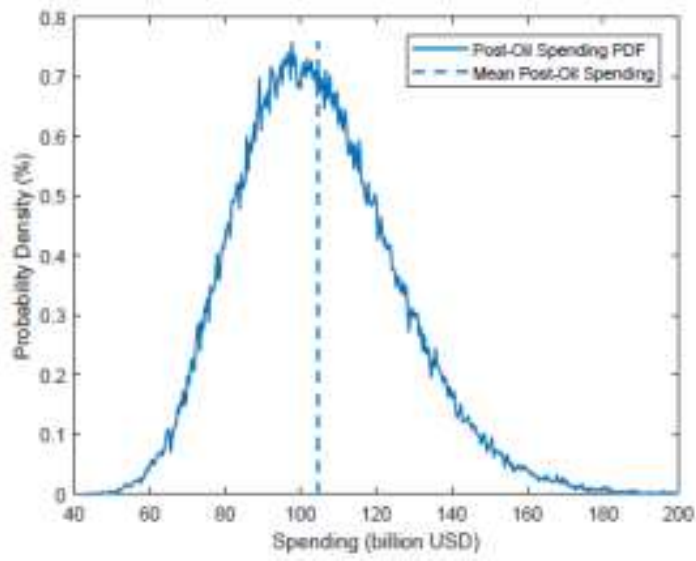

3.3 Equivalent Precautionary Premium $\left(x_{t}\right)$

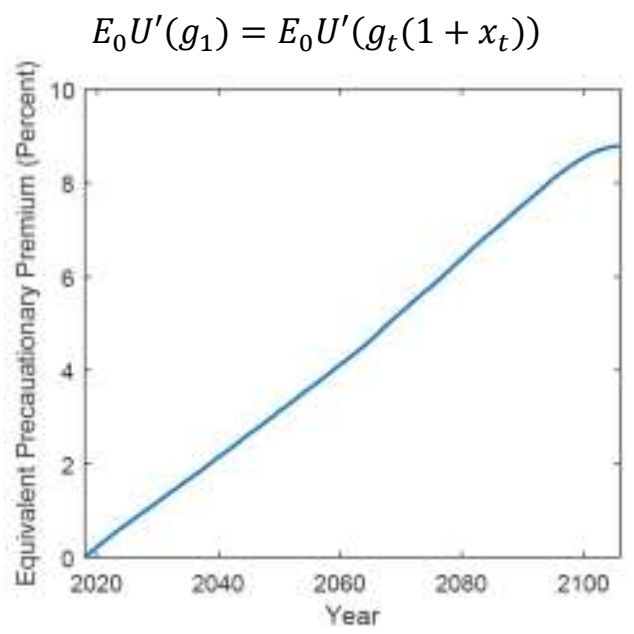

Note: 89 periods of oil price are simulated for 100,000 times given initial oil price at its long-run mean.

26. The utilitarian framework allows to gauge the magnitude of intergenerational inequity under risk aversion. According to Jensen's inequality, the Euler equation implies that the expected marginal utility of the post-oil generation (at time $\mathrm{T}$ ) is smaller than that of the current generation: $U^{\prime}\left(g_{t}\right)>U^{\prime}\left(E_{t}\left[g_{t+T}\right]\right)$. One way to measure the resulting intergenerational inequity is an equivalent precautionary premium $(x)$ - in the terminology of Kimball (1990) - or the additional annual consumption that would equate the expected marginal utilities of these two generations: $U^{\prime}\left(g_{t}\right)=E_{t} U^{\prime}\left(g_{t+T}(1+x)\right)$. This premium can be interpreted as compensation to future generations for the higher uncertainty they face. In our calibration, $x$ amounts to 9 percent - the amount by which post-oil government spending would need to increase to achieve intergenerational equity. This would require the post-oil 
generation inheriting an additional $\$ 300$ billion in wealth (14 percent in additional financial wealth if non-oil income is excluded or 78 percent of UAE's 2017 GDP). Note also that the equivalent precautionary premium or intergenerational inequity between the initial and subsequent generations increases in proportion to the risk they face (panel 3.3 in Figure 3). By contrast, under PIH, the expected path of consumption is flat across generations and the Euler equation breaks down. This failure to compensate future generations for the higher risks they face leads to intergenerational inequity under PIH.

27. To recap, PIH produces intergenerational inequity because it is not prudent in the definition of Kimball (1990) in that it transfers risk to future generations but does not take measures to compensate them for the resulting mean-preserving spread. ${ }^{11}$ Moreover, $\mathrm{PIH}$ is not well-anchored because it pegs consumption to wealth which is itself non-stationary. From this perspective, it is not consistent with long-term sustainability. The next section discusses overcoming these shortcomings in turn.

\section{Hallmarks of Optimal Policy}

\section{A. Prudence}

28. The principles of intertemporal allocation of consumption in the presence of uncertainty are well known. When agents are risk averse in the sense of Arrow (1965) and Pratt (1964), the optimal consumption path involves precautionary saving (Leland, 1968). The amount of such saving is related to the degree of prudence and the volatility and persistence of shocks (Kimball, 1990). What pattern of precautionary saving is needed to achieve intergenerational equity in oil exporting countries?

29. Answering this question requires finding a policy that satisfies the equilibrium conditions (7) and (9) in every period. The model does not have an analytical solution and we employed numerical methods to discretize the state space and shocks (as per Tauchen, 1986). Assuming that, at the time of oil exhaustion (when the oil price uncertainty clears), future generations will follow PIH (which is optimal under no uncertainty), the solution procedure is implemented recursively backward, starting from period $T-1$ (see Appendix III). Figure 4 compares the performance of this prudent policy to $\mathrm{PIH}$.

30. A prudent policy requires precautionary savings in early periods of oil extraction, i.e. by generations which face least uncertainty. Over time, these savings increase the stock of financial wealth and the government's dividend income. As the oil price uncertainty faced by subsequent cohorts begins to diminish with the declining importance of oil, the precautionary saving motive also weakens. As a result, government spending is gradually increased and is higher than under PIH in the second half of the simulation period.

\footnotetext{
${ }^{11}$ Kimball associates prudence with the precautionary saving motive and measures it by the ratio of third and second derivatives of the utility function. Grater prudence implies larger precautionary savings.
} 


\section{Figure 4. Prudent Policy: Simulation Results}

4.1. Oil Price and Spending under Prudent and PIH Policies: one simulation

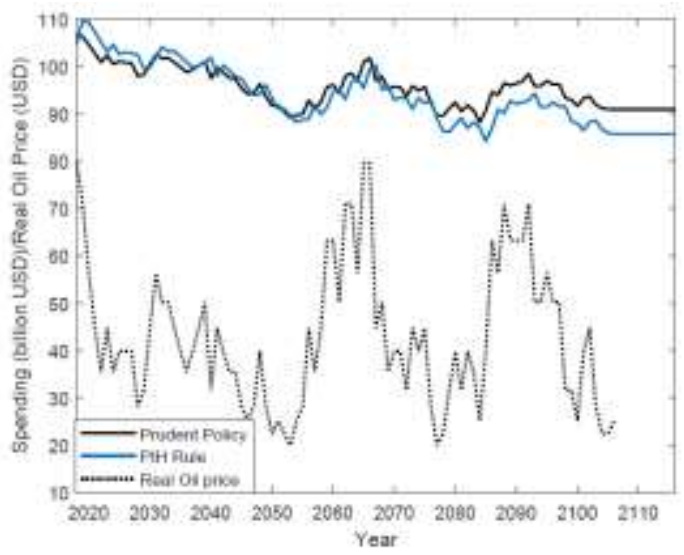

4.3. Wealth under Prudent Policy: 100,000 Oil Price Simulations

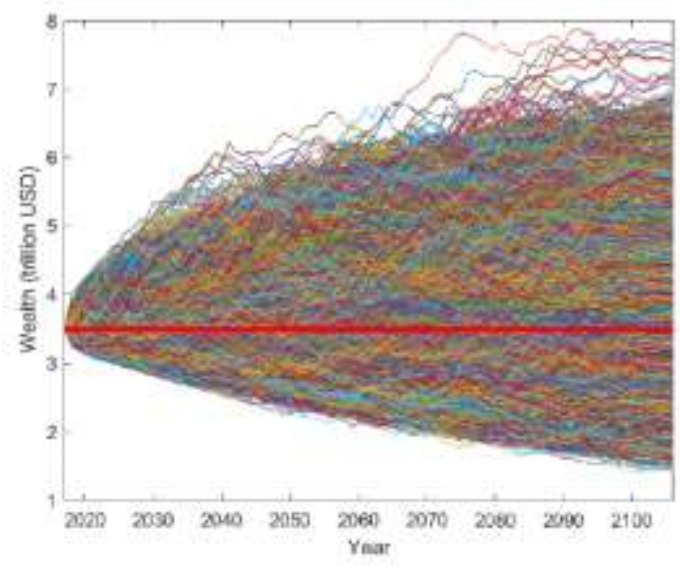

4.5. Simulated Expectation of Spending,

$$
E_{0}\left[g_{t}\right]
$$

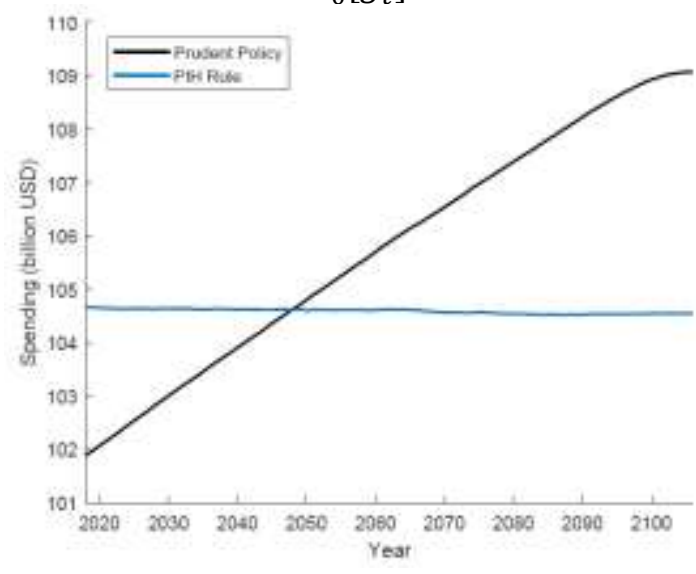

4.2. Evolution of Wealth under Prudent and PIH Policies: One Simulation

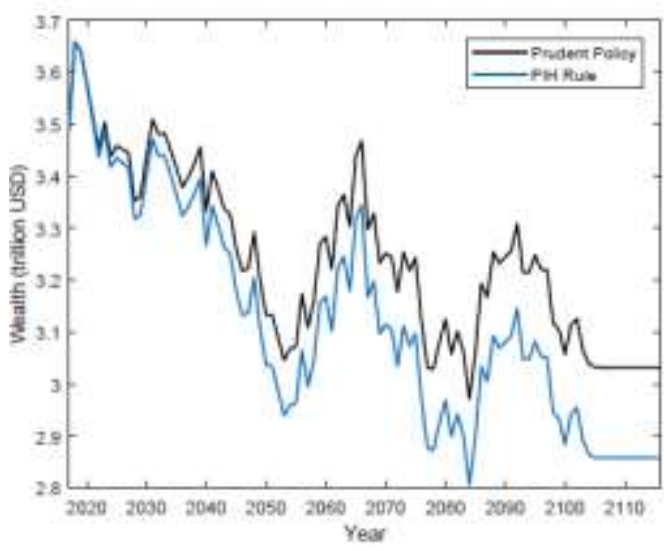

4.4. Post-oil Wealth under Prudent and PIH policies: Empirical Distribution from 100,000 Oil Price Simulations

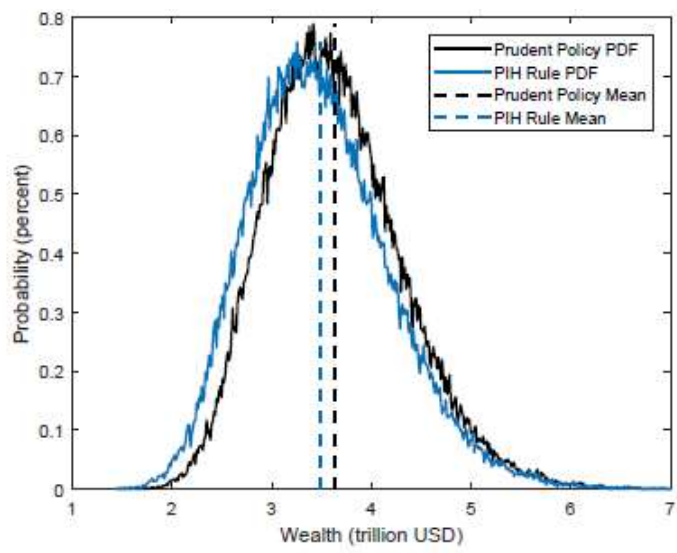

4.6. Simulated Coefficient of Variation of Spending, $\sigma_{t}^{g} / E_{0}\left[g_{t}\right]$

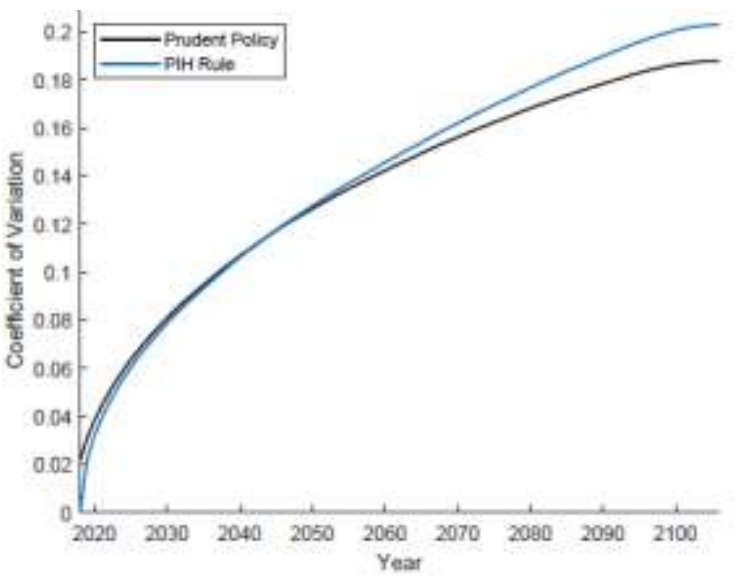


31. These observations have been correctly predicted by Barnett and Ossowski (2002) and explored more rigorously by Engel and Valdes (2000), Bems and Carvalho (2011), van der Ploeg (2014), and IMF (2015) among others. We offer two additional insights to these studies:

- $\quad$ Prudence implies targeting a higher-than-initial level of post-oil wealth and spending. As predicted by Kimball (1990), the compensatory precautionary premium implies a shift in the distribution of $w_{T}$ and $g_{T}$ - their expected values are higher than the initial values (panel 4.4 and 4.5). It is useful to think of this precautionary premium $\left(E_{0} w_{T} / w_{0}>1\right)$ as risk compensation to the post-oil generation. In our calibration, this premium is 4 percent ( 7 percent if non-oil revenues are excluded). Intuitively, the PIH rule fails to achieve intergenerational equity because it maintains a constant expected level of spending across generations which does not compensate future cohorts for the greater risks they face.

- $\quad$ Achieving intergenerational equity is not equivalent to ensuring long-term sustainability. Risk compensation is embedded into government spending as a trend, i.e. consumption and wealth are expected to increase over time, whereas they are expected to remain constant under PIH (panel 4.5 in Figure 4). The shift in the distribution of post-oil wealth occurs primarily due to this trend with a relatively small impact on overall volatility (panels 4.4 and 4.6 in Figure 4). Meanwhile, non-stationarity of wealth and government spending continue to echo through the model which still lacks wealth-stabilizing features (panel 4.3). While prudent, this policy remains inconsistent with long-term sustainability because of the large tail risks faced by future generations. The remedy to this is presented next.

\section{B. Anchoring}

32. Schmitt-Grohe and Uribe (2003), among others in the literature on open economy models, discuss various ways of inducing stationarity of net foreign assets in open economy models, such as assuming a wealth- or debt-dependent discount rate (Uzawa preferences) or risk premium, or portfolio adjustment costs. ${ }^{12}$ Regardless of the motivation, these strategies work to establish a link between wealth and the intertemporal marginal rate of substitution of consumption, just as physical capital is related to it in Hartwick's framework. Stationarity is essentially induced by incorporating an incentive to stabilize net foreign assets or wealth

\footnotetext{
12 Ghironi (2008) proposes an overlapping generations model structure. See also Obstfeld (1982) and Uzawa (1968). The IMF's Global Integrated Monetary and Fiscal Model (GIMF) uses overlapping generations and an endogenous risk premium (Kumhof and others, 2010).
} 
around an assumed (and generally time-invariant) equilibrium value, such as some long-term average or simply zero. ${ }^{13}$

33. Extending their logic to this setting calls for identifying an appropriate level of wealth around which a stabilization incentive could be embedded into the model. Limited resource horizons and the intergenerational equity considerations discussed above make past averages a poor indicator of what wealth should be going forward. Rather, prudence calls for targeting a level of wealth that is higher and incorporates a precautionary premium to compensate future generations for the risk they face. With this in mind, anchoring fiscal frameworks by a level of wealth that is intended to be left to post-oil generations holds more promise of fostering intergenerational equity. In addition to anchoring, such a target would have additional benefits of infusing policy frameworks with greater transparency and discipline.

34. A simple way of embedding a wealth stabilization incentive into the model is to add a notional penalty $\frac{\varphi}{2}\left(\bar{w}-w_{t}\right)^{2}$ into the government's budget constraint, akin to portfolio adjustment costs used in the literature. ${ }^{14}$ Here, $\bar{w}$ can be interpreted as the level of wealth that is intended to be left behind for future generations, i.e. the assumed long-term anchor. As discussed earlier, prudence requires setting it above the initial level of wealth. ${ }^{15}$ This modification alters the optimality condition (11) as follows:

$$
U^{\prime}\left(g_{t}\right)=\frac{E_{t} U^{\prime}\left(g_{t+i}\right)}{1-\varphi\left(\bar{w}-w_{t}\right)}, \forall i>0
$$

Consumption growth is now anchored to achieving targeted wealth which is also its long-term equilibrium. The reasons for and the mechanism of adjustment are similar to the mean-reversion of physical capital in Hartwick's closed-economy model. When wealth falls below the target $\left(w_{t}<\bar{w}\right)$, the adjustment cost acts like an interest rate hike-lowering consumption growth and raising saving so that wealth can gravitate towards the target. The parameter $\varphi$ captures the strength of wealth stabilization motive.

35. Wealth anchoring significantly reduces the amount of uncertainty passed onto future generations (Figure 5). Volatility is spread more evenly over time, and both wealth and government expenditure display reversion to their equilibrium levels - this policy is now consistent with long-term sustainability. The latter also contributes to improving

\footnotetext{
13 The overlapping generations setting is an exception, where equilibrium is pinned down with an assumption that new cohorts are born without financial assets. It is less obvious how to motivate such a structure in situations where oil wealth is centrally owned and citizens are born with a claim to a share of that wealth.

${ }^{14}$ In line with common practice, the penalty is assumed to be rebated back to the government as a lump sum, i.e it serves only to induce stationarity of wealth but does not impose an actual cost on public finances.

${ }^{15}$ In the simulations, the precautionary premium of $\bar{w} / w_{0}$ was set at 2 percent and $\varphi$ at 0.00003 . The small value of the latter is explained by the relative scales of $g$ and $w$.
} 
intergenerational equity, owing to a larger reduction in the standard deviation of post-oil wealth (panel 5.4 in Figure 5).

36. Finally, it is worth highlighting, that wealth anchoring also requires somewhat greater short-term volatility of government expenditure relative to PIH. Note, that the speed of mean reversion in wealth and the reduction in post-oil tail risks would be larger for higher values of $\varphi$. At the same time, a higher $\varphi$ would require expenditure to more actively offset contemporaneous shocks, making spending more volatile. This additional volatilityalthough still small relative to the volatility of the oil price - is a necessity, dictated by the wealth stabilization motive. It is also a manifestation of the volatility tradeoff, which is discussed next.

\section{Figure 5. Wealth-Anchoring Policy: Simulation Results}

5.1. Spending under Wealth-Anchoring and PIH Policies: One Simulation

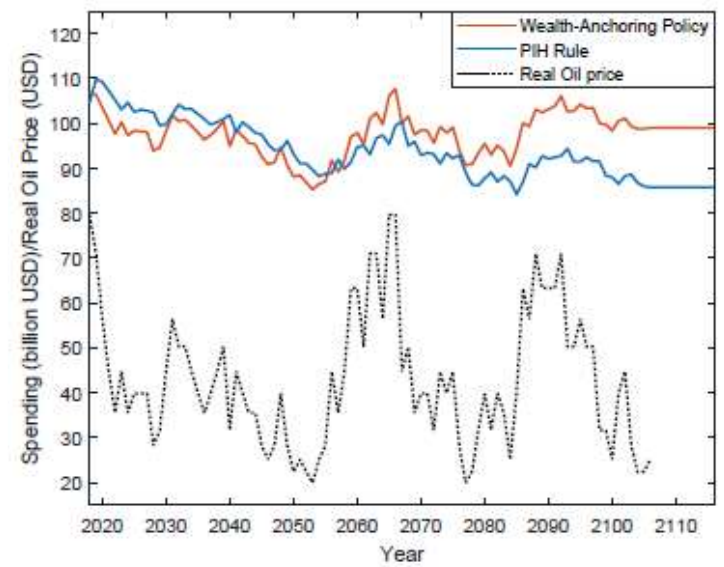

5.3. Wealth Paths under Wealth-Anchoring Policy: 100,000 Oil Price Simulations

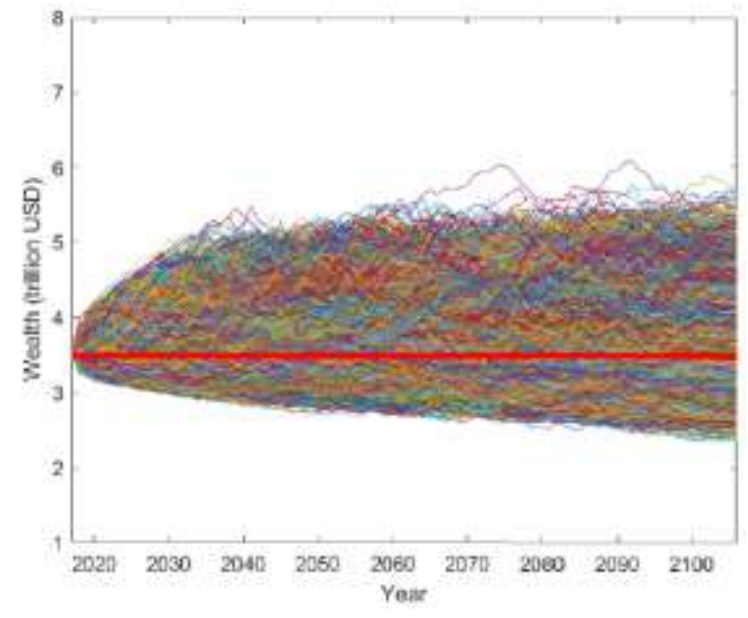

5.2. Wealth under Wealth-Anchoring and PIH Policies: One Simulation

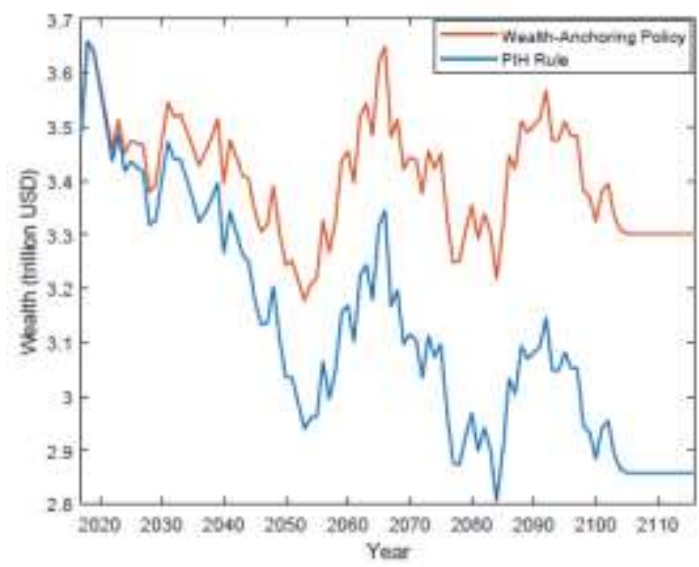

5.4. Post-Oil Wealth under Wealth-Anchoring and PIH policies: Empirical Distribution from 100,000 Oil Price Simulations

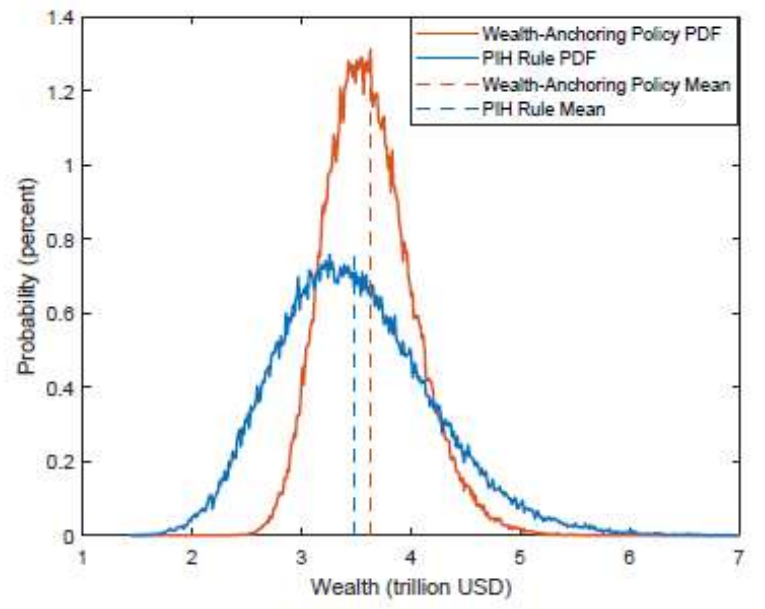




\section{Rethinking Fiscal Policy}

\section{A. Recognizing the Volatility Tradeoff}

37. The apparent choice between smoothing expenditure and stabilizing wealth has not been sufficiently recognized in the fiscal policy discourse. This tradeoff becomes apparent from equation (8) reproduced below:

$$
w_{t}=(1+r) w_{t-1}-g_{t}+\tilde{\phi}_{t}
$$

The effects of oil price shocks $\left(\tilde{\phi}_{t}\right)$ will impact either wealth or government spending or both. How this impact is distributed between wealth and expenditure, in turn, is determined by the policy governing $g_{t}$. When the latter is smoothed, wealth must fully absorb shocks. Conversely, stronger wealth anchoring requires more aggressive offsetting of shocks and, hence, more volatile government expenditure.

38. To illustrate this further, consider polar scenarios of wealth stabilization and consumption smoothing. For wealth to be maintained intact $\left(w_{t}=w_{0}, \forall t\right.$, Figure 6 , right panel), government spending must fully neutralize oil price shocks and its resulting volatility is likely to be unrealistically high. ${ }^{16}$ Such a policy would be unfairly biased toward future generations. Similarly, extreme consumption smoothing will favor oil-producing cohorts by requiring wealth to absorb all oil price volatility. In this case, wealth nearly runs out due to the predominance of negative shocks in the simulation (Figure 6, left panel).

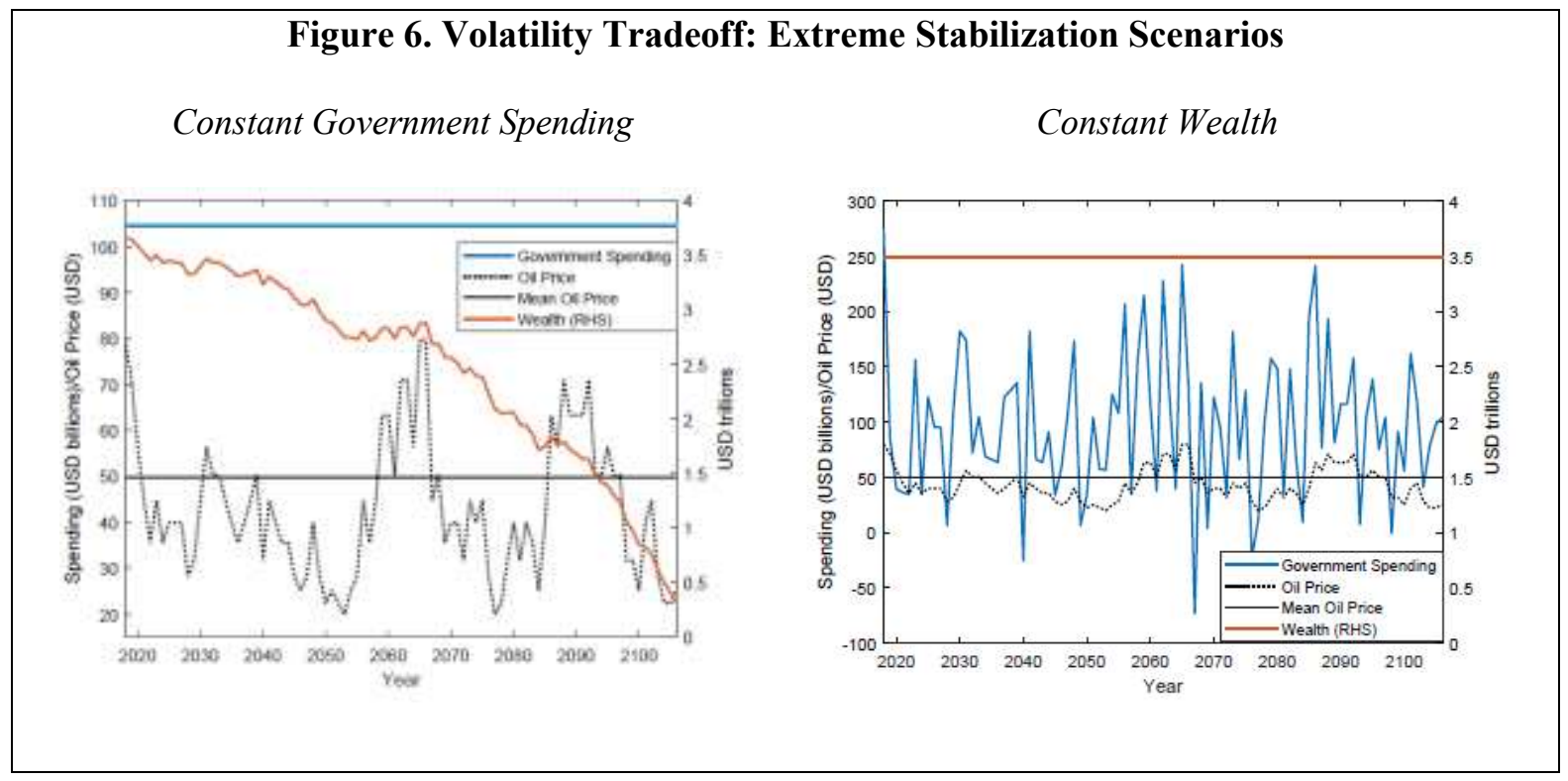

\footnotetext{
16 The level of spending is not always sufficient to fully offset shocks and it turns negative in the simulation.
} 


\section{B. Policy Implications}

39. Much of the discourse on fiscal policy in oil exporting countries can be framed in terms of the volatility tradeoff as any policy can be characterized as an intermediate case of the two extremes described above. Together with the need for prudence and anchoring, discussed earlier, this perspective sheds new light on the existing fiscal policy paradigm and constitutes the crux of our proposed rethinking.

\section{Conceptual Framework:}

- $\quad$ Countries must balance an 'impossible trinity'. One implication of the volatility tradeoff is that simultaneously achieving expenditure smoothing, wealth preservation (long-term sustainability), and intergenerational equity is impossible. The "price" of smoother spending is higher volatility of wealth. The consequence of the latter, in turn, is increased intergenerational inequity. Therefore, the existing fiscal policy paradigm should be re-framed as seeking to balance these objectives rather than achieving them at the same time.

- $\quad$ Countries need to form a view of how to pursue intergenerational equity. It can be achieved with either more aggressive wealth stabilization (higher $\varphi$ ) or-keeping the time profile of uncertainty unchanged - larger risk compensation to future cohorts (higher precautionary premium $\bar{w} / w_{0}$ ) by targeting a higher level of post-oil wealth. In terms of the 'impossible trinity,' targeting a higher level of post-oil wealth would allow oil-producing generations to enjoy a consumption path that is smoother but, on average, lower. Conversely, a lower precautionary premium would allow oil-producing generations to consume more on average, but, in return, they must endure increased volatility of their own consumption to stabilize wealth. This interdependence between the chosen long-term fiscal anchor and the short-term fiscal strategy required to achieve intergenerational equity appears absent under the existing paradigm.

\section{Fiscal Framework Design:}

- $\quad$ Fiscal frameworks should focus on wealth rather than expenditure targets.

Expenditure benchmarks can be misleading if they are not derived from a strategy to achieve targeted wealth - the ultimate determinant of fiscal sustainability and intergenerational equity. The PIH expenditure benchmark is a point in case. First, it pegs expenditure to a past level of wealth and provides little forward-looking guidance. Second, the benchmark is not only volatile, but also non-stationary, and thus poorly equipped to serve as a long-term anchor. Finally, the pitfall of focusing on achieving an expenditure benchmarks in fiscal frameworks is that it can lose track of wealth when the latter is non-stationary.

- Wealth stabilization requires some degree of procyclicality vis-à-vis the oil price. The intuition is simple: in times of negative shocks, wealth declines and, therefore, its recovery requires lower consumption, and contrariwise. By contrast, a countercyclical consumption policy — saving more in good times and spending more on rainy days_-would 
produce a more procyclical and volatile wealth. ${ }^{17}$ In turn, more volatile wealth would increase intergenerational inequity and weaken long-term sustainability. This is not to say that there is no room for countercyclical policies in a more general setting. However, arguments in favor of countercyclical short-term policies must be weighed against the benefits of procyclicality from the long-term intergenerational equity and sustainability perspectives. ${ }^{18}$ More generally, the volatility tradeoff implies that long- and short-term fiscal policy objectives may not be always perfectly aligned and require careful balancing.

\section{Fiscal Targets:}

- $\quad$ Post-oil wealth target is a strong long-term fiscal anchor. Besides being forwardlooking and facilitating long-term sustainability, anchoring fiscal frameworks by a level of wealth that is to be left to post-oil generations has a strong benefit of binding together the rest of the fiscal framework. To see this, in keeping with our conceptual framework, note, that the precautionary premium implied by such a target identifies the chosen degree of prudence. In turn, the latter narrows the set of short- and medium-term policies which would be feasible from the intergenerational perspective.

- $\quad$ Medium-term fiscal benchmarks should aim at raising wealth. The need to target a higher level of wealth in the pursuit of intergenerational equity under uncertainty warrants reconsideration of the usual prescription that policies should seek to maintain wealth constant. Furthermore, the discussion of prudence also implies that wealth should increase in a concave fashion over time - because the burden of precautionary savings mostly falls on early generations. An example of such a medium-term wealth target path is depicted in Figure 10 (panel 10.3). It is derived from simulation of a simple policy, discussed next, which incorporates the principles of our proposed rethinking.

\section{Prudent Wealth Stabilization (PWS) Rule}

40. Translating the intuition and insights developed above into policy is complicated by the limited applicability of numerical solutions. Their implementation is technically complex and insufficiently transparent, making policy discussions and communication difficult. This puts a premium on identifying simple rules that can approximate optimal policies and their consistency with intergenerational equity and long-term sustainability.

\footnotetext{
${ }^{17}$ IMF (2015) finds that most commodity exporters have been procyclical over the last decade or so. In our setting, attempts to simulate a countercyclical fiscal policy produced unsustainably explosive paths of wealth.

18 This line of reasoning can be generalized to all countries: volatility of public debt would be important if intergenerational equity and risk aversion considerations were to be added to debt sustainability frameworks. Minimizing this volatility and tail risks would similarly call for some degree of procyclicality.
} 
41. To this end, we propose a practical alternative to PIH- prudent wealth stabilization (PWS) policy. It allows to replicate key features our proposed rethinking - prudence, anchoring, and balancing the volatility tradeoff — while retaining PIH's appeal of simplicity. ${ }^{19}$ PWS takes the following form:

$$
g_{t}=f_{t}+\alpha\left(w_{t-1}-\gamma w_{0}\right)
$$

The first term on the right-hand side $\left(f_{t}\right)$ is meant to capture short-term objectives of fiscal policy, reflecting its role in, for example, macroeconomic stabilization, maintaining competitiveness, and facilitating growth of the non-energy sector. Because these features are not modeled here, the discussion below sets $f_{t}=r w_{t-1}$. In other words, let us assume, for now, that the short-term policy goal is consumption smoothing (as under PIH) - the first part of the impossible trinity: ${ }^{20}$

$$
g_{t}=r w_{t-1}+\alpha\left(w_{t-1}-\gamma w_{0}\right)
$$

42. The second term in (14) captures our proposed framework for achieving the longterm goals of sustainability and intergenerational equity. It connects wealth with its initial value $\left(w_{0}\right)$ using two parameters:

- Wealth stabilization factor, $\alpha>0$, which calls on government spending (saving) to decrease (increase) when wealth is below its target level $\left(\gamma w_{0}\right)$, thereby inducing wealth to gravitate to this equilibrium. This makes the policy wealth-stabilizing.

- $\quad$ Precautionary premium, $\gamma$, which captures the risk compensation embedded in the target for post-oil wealth. When $\alpha$ is not exorbitant - i.e. when the risk assumed by oilextracting generations does not exceed the risk faced by non-oil generations - target wealth needs to be set higher than the initial wealth: $\gamma>1$. This makes the policy prudent.

43. Furthermore, in practical applications, we propose to calibrate PWS as follows. First, the average level of government spending in relation to wealth provides an appropriate scale for the wealth stabilization factor $(\alpha)$. For countries which have been close to following PIH, for example, $\alpha=r$ would be a good initial ballpark. Next, the rule can be simulated to obtain post-oil values of wealth for different values of $\gamma$. Intergenerational equity can be imposed by finding a value of $\gamma$ which satisfies the optimality condition (11) between the initial and postoil periods: $U^{\prime}\left(g_{0}\right)=\beta(1+r) E_{0} U^{\prime}\left(g_{T}\right)$, where the right-hand-side is calculated on the basis of simulations. Although this method does not ensure strict intergenerational equity-i.e.

\footnotetext{
${ }^{19}$ Another option is to linearize (13) which would relate expected consumption growth to deviations of wealth from the target. Compared to PWS, this option would lose the consumption-smoothing component, which is not explicitly modeled, and would also include an expectation term making implementation less transparent.

${ }^{20}$ Ideally, this term should capture a more suitable short-term fiscal policy paradigm, including fiscal response to productivity, external demand, and other shocks (see Section VI).
} 
equity between every single generation during the oil-extraction period, which would require the use of numerical methods - it provides a reasonable approximation by enforcing it at two end points.

44. This proposed calibration method also captures the essence of the volatility tradeoff. For any given realistic wealth stabilization factor, there is a unique precautionary premium which ensures intergenerational equity between the initial and post-oil generations. ${ }^{21}$ Figure 7 presents the optimal values of $\gamma$ corresponding to various values of $\alpha$ in our calibration. Weak wealth stabilization (low $\alpha$ ) requires a larger precautionary premium. As wealth stabilization strengthens and volatility is shared more evenly by generations, the required prudence factor declines.

\section{Figure 7. Volatility Tradeoff in PWS Policy}

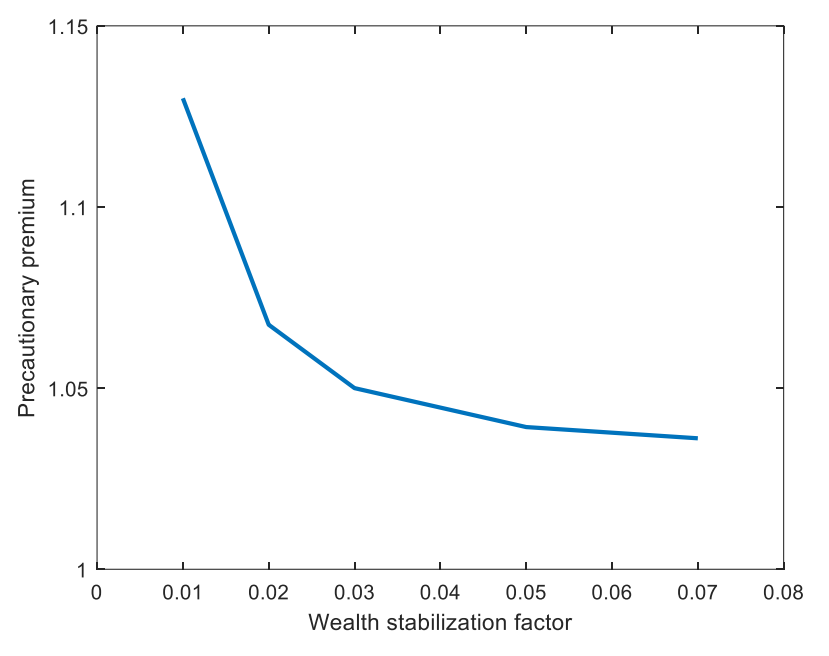

45. Figure 8 shows the performance of this rule relative to PIH and the statistical properties of post-oil wealth. Key features of the optimal policies discussed earlier — prudence and anchoring — are easily recognizable in these charts. Targeting a precautionary premium involves initial generations saving more and allows higher average consumption of future generations. The wealth stabilization factor ensures stationarity, notwithstanding a series of negative oil price shocks which cause a precipitous decline under PIH. Post-oil wealth is thus both higher and more certain under PWS than under PIH (panel 8.4).

\section{Intuition}

46. Consider the statistical properties of government expenditure and wealth under PIH and PWS (Figure 9). As mentioned earlier, under PIH, the ex ante expectation (i.e. expectation as of the initial period) of wealth and government expenditure is constant, but their volatility is rising over time, reflecting non-stationarity and giving rise to intergenerational inequity. PWS remedies these shortcomings in two ways:

\footnotetext{
${ }^{21}$ Values of $\alpha$ were considered realistic by comparing the volatility of government spending with that of the oil price. When $\alpha$ approached about 0.1 , government expenditure became nearly as volatile as the oil price. In the baseline setting, we set $\alpha=0.03$ and $\gamma=1.05$. The latter implies additional wealth accumulation of $\$ 173$ billion during the years of oil extraction (45 percent of UAE's 2017 GDP).
} 
- $\quad$ Prudence. Note, that the term $\alpha\left(w_{t-1}-\gamma w_{0}\right)$ induces an overall rising trend in wealth as it converges to its targeted level, forcing additional saving. This convergence is gradual and asymptotic. ${ }^{22}$ Because it is pursued by closing a fixed fraction of the remaining gap in each period, most of it is achieved early on (panel 10.3). Thus, replicating the property of prudent policy, the burden of precautionary savings largely falls on initial generations, who face less uncertainty and whose expected consumption is lower than under PIH (panel 9.1).

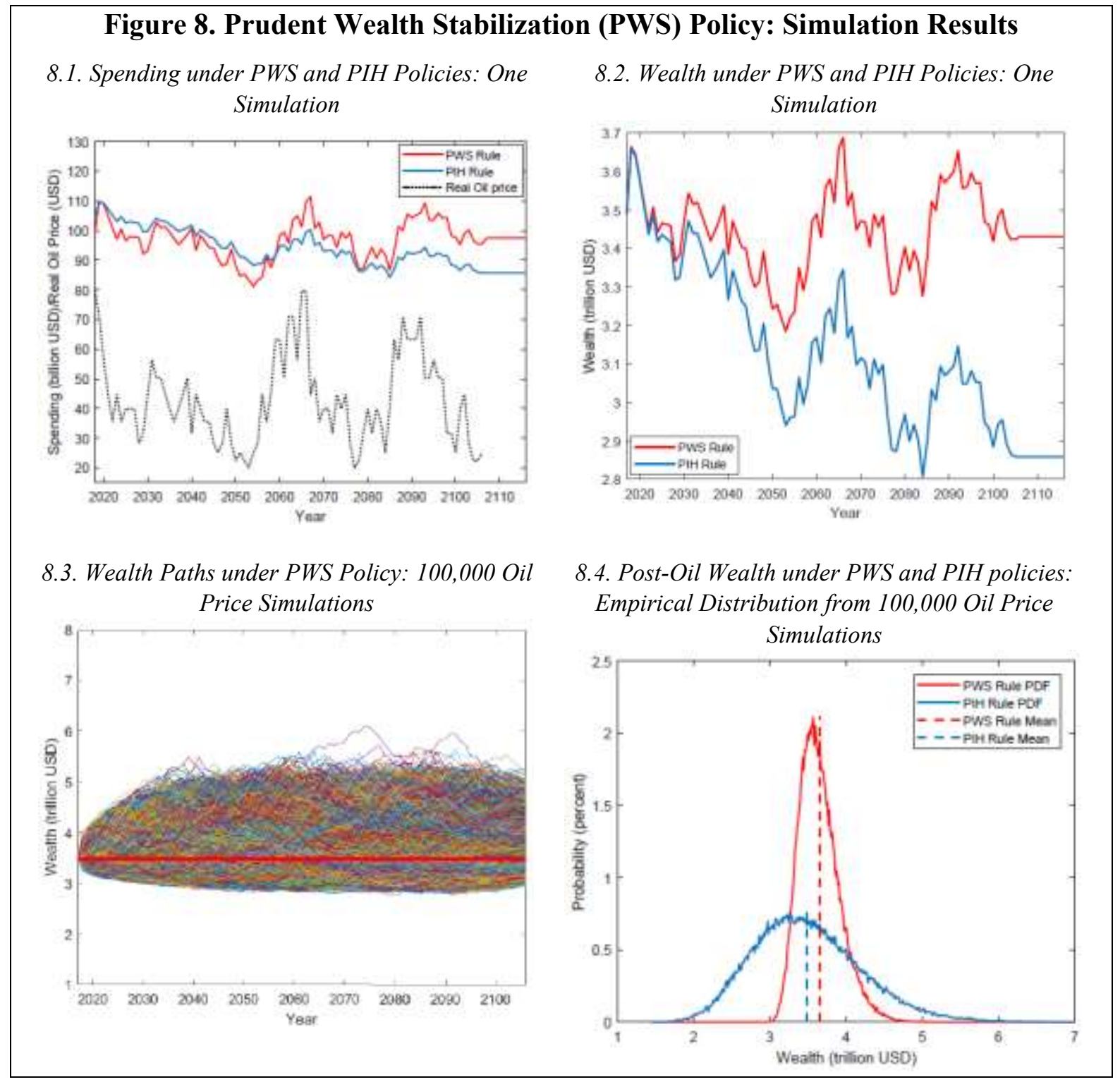

${ }^{22}$ In our calibration, although expected wealth is rising, its targeted level would not be achieved by the time of oil exhaustion even in the absence of shocks (a higher $\alpha$ would accelerate convergence). 
- Anchoring. How much is actually saved/spent in each period also depends on shocks. Negative shocks to wealth widen the gap between its actual value and the target $\left(w_{t-1}-\gamma w_{0}\right)$, and induce additional saving. Owing to this wealth stabilization, volatility of wealth, measured by the coefficient of variation in Monte Carlo simulations, is significantly reduced compared to $\mathrm{PIH}$ and is more stable across generations (panel 9.4). ${ }^{23}$ By contrast, short-term volatility of government spending is higher than under $\mathrm{PIH}$, reflecting wealthstabilizing response to shocks, but its long-term volatility is lower due to stationarity.

\section{Figure 9. Statistical Properties of Wealth and Government Spending under PWS and PIH Rules: 100,000 Monte Carlo Simulations}

9.1. Expected Spending $E_{0} g_{t}$

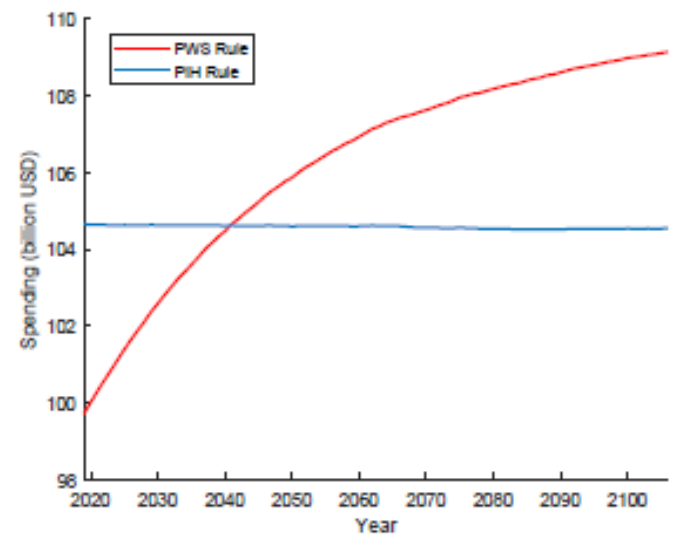

9.3. Expected Wealth $E_{0} w_{t}$

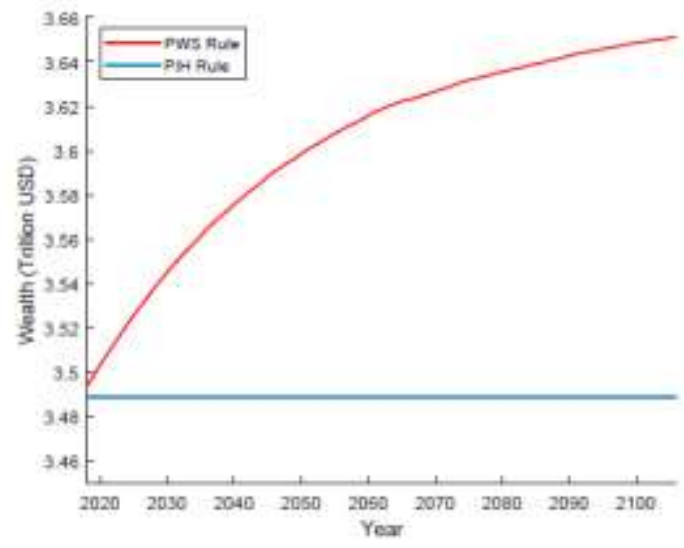

9.2. Spending: Coefficient of Variation, $\sigma_{t}^{g} / E_{0} g_{t}$

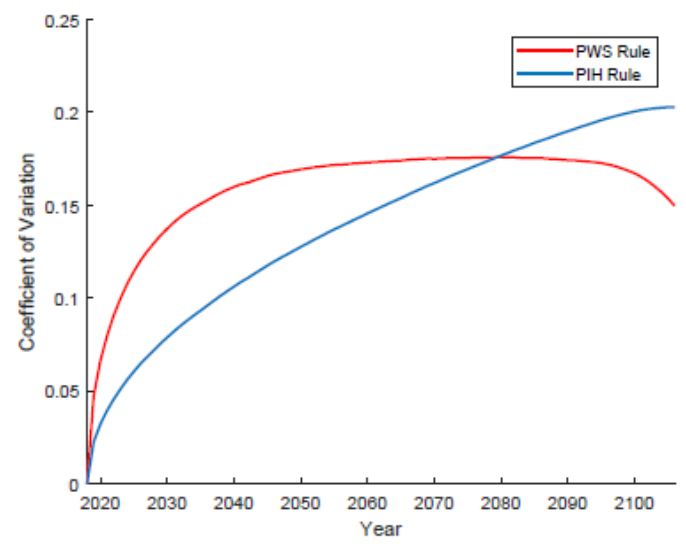

9.4. Wealth: Coefficient of Variation, $\sigma_{t}^{w} / E_{0} w_{t}$

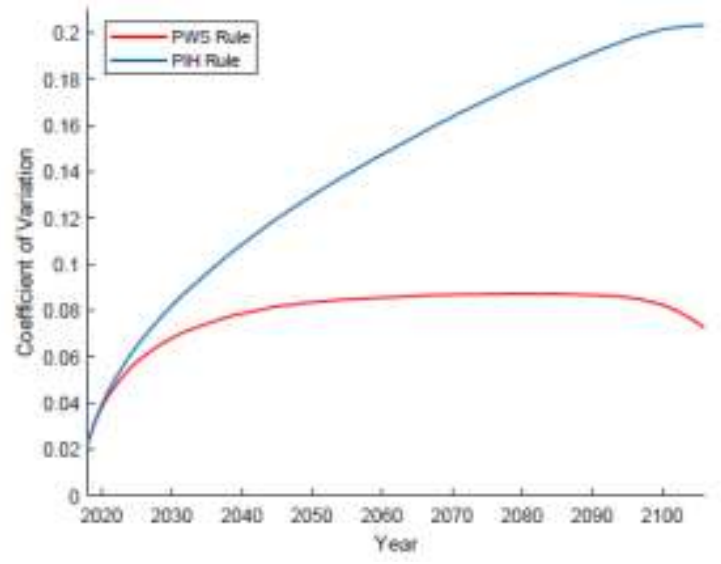

${ }^{23}$ Expected volatility declines toward the end of the simulation period when oil wealth's weight in total wealth and the impact of oil price shocks on wealth rapidly diminish. 
47. In sum, PWS captures the key insights from our analysis and translates them into a fiscal framework that is: i) anchored by a long-term target for post-oil wealth $\left(\gamma w_{0}\right)$; ii) supported by medium-term benchmarks that are consistent with this target (panel 9.3); and iii) prescribes a response of annual government expenditure to shocks that balances longterm goals of intergenerational equity and sustainability with expenditure smoothing, assuming the latter as the goal of short-term fiscal policy.

\section{Additional Considerations}

\section{PWS Implementation Issues}

48. In practical applications of PWS, policy makers would need to decide how to balance the volatility tradeoff, i.e. the appropriate combination of the wealth stabilization factor $(\alpha)$ and the precautionary premium $(\gamma)$. Equivalently, this amounts to choosing between the volatility of government expenditure (panel 9.2) and that of wealth (panel 9.4). This choice of a precautionary premium must reflect countries' preferences, such as the importance they attach to the well-being of future generations and their aversion to risk. Subject to these preferences, calibration of PWS can seek to minimize the cost of short-term expenditure volatility, e.g. due to destabilizing effects on non-oil growth. This question merits further exploration in a setting where these linkages are explicitly modeled.

49. Another issue that is likely to arise in practical applications is whether the target for post-oil wealth should remain fixed. A case can be made for this target to be periodically revised. Structural changes to the base model - such as a revision of oil reserves or reconsideration of the oil price's stochastic properties - would naturally warrant such revisions. A more difficult question is whether such revisions are warranted by transitory developments. For example, following an oil price shock in period $t$, a country may decide that the long-term target established in the previous period is no longer optimal and be tempted to revise it.

50. This time inconsistency conundrum, which applies to both PWS and PIH, does not have an obvious resolution from the intergenerational perspective. The discretion that comes with reoptimizing the long-term anchor potentially makes the latter volatile. Solving for such

a policy must proceed recursively backward and in the absence of a fixed long-term anchor is likely to result in non-stationarity, as we have seen in section IV. It is, therefore, not clear whether the framework permits a policy that is both stationary and optimal from both time consistency and timeless perspectives. Overlapping generations frameworks may hold some promise in toward these ends.

51. At the same time, the long-term benefits of anchoring the framework with a fixed post-oil target are significant, especially when compared to PIH. Akin to inflation targeting frameworks, in which a long-term target is often specified in numerical rather than functional form and thus is not time-consistent, PWS provides sufficient flexibility to deviate from the target and pursue it gradually. At the same time, a commitment to a fixed forward-looking 
long-term target imposes sufficient discipline on current generations' saving policy to make it appealing from the timeless perspective.

52. Finally, alternative ways of inducing stationarity and targeting wealth merit further investigation. For example, the simple shortcut to introduce the wealth-anchoring motive here could be replaced with more elaborate incentives, such as asymmetric targets or imposing a floor on wealth $\left(w_{t} \geq \underline{w}, \forall t\right)$, akin to ceilings in debt sustainability frameworks.

\section{Public Investment}

53. Many oil exporters share the ambition of diversifying and developing their economies through active public investment. In this context, recent extensions of the basic PIH framework have focused on incorporating public investment and its potential impact on growth (Berg et al., 2012, IMF 2012, 2015). While addressing a highly relevant omission of the base model, these modifications do not change its properties with respect to intergenerational equity and long-term sustainability. ${ }^{24}$ Specifically, when the role of public investment is incorporated:

- $\quad$ Saving is divided between financial and physical assets which earn a higher average rate of return. The presence of an alternative saving technology (public investment) creates an intra-temporal choice of how to allocate the public investment portfolio between physical capital and financial wealth. Under diminishing marginal returns to the former, the optimal level of public capital equates its marginal product net of depreciation with the opportunity cost of investing in financial assets. Therefore, average return on wealth is higher than the world interest rate, owing to the higher average yield from physical capital.

- Inter-temporal allocation of consumption is unaffected by public investment. The intra-temporal investment portfolio allocation does not affect the inter-temporal choice of how much to consume and save, which continues to be governed by the consumption-Euler equation (11). ${ }^{25}$ Importantly, it remains independent of wealth. The higher average return on wealth created by physical capital raises average consumption level across all generations, i.e. the PIH benchmark must be revised to incorporate the excess returns from physical capital, leaving intergenerational distribution of consumption unaffected.

\footnotetext{
${ }^{24}$ See Appendix IV which discusses a setting where some of the oil wealth is invested to create a productive stock of physical capital, which represents the non-oil non-financial wealth in Figure 1.

${ }^{25}$ Araujo et al. (2016) examine a setting of a resource-rich economy that is, nevertheless, a net borrower facing tight borrowing constraints and an endogenous (convex) risk premium anchored by an exogenous debt limit which ensures stationarity. They find that, by relaxing borrowing constraints, resource revenue could lead to lower savings with frontloaded investment and consumption and, therefore, lower current account balances. This setting conflates the inter-temporal and intra-temporal choice as only the borrowing interest rate (subject to the risk premium) is relevant. This would not be applicable to more "mature" oil exporters which also save in financial assets or are able to finance their public investment needs out of past savings.
} 
- $\quad$ Wealth remains non-stationary. A model with both financial and physical capital investments is an intermediate case between the basic PIH model of section II and Hartwick's framework. Although the equilibrium level of physical capital—which must now be included in the accounting of total wealth - can be pinned down (as discussed in Section III), overall equilibrium level of wealth remains indeterminate and wealth itself remains nonstationarity. Thus, the intergenerational equity and long-term sustainability concerns of the basic PIH framework continue to persist.

54. In countries where the initial level of physical capital is far below optimal and - due to various constraints - can only be raised gradually, the portfolio allocation of investment would vary across generations. Early generations would invest more in physical capital during the periods of its accumulation and increasingly favor financial assets once physical capital reaches its optimal level. This has sometimes been interpreted as a general strategy of drawing down of government wealth to permit frontloading of expenditure. This conclusion must be understood in the specific context of how spending and saving are defined:

- In our base model, "spending" and "consumption" could be used interchangeably and were clearly distinct from "saving" and "investment" which could also be used interchangeably. "Spending" and "consumption" captured "spending of wealth," i.e. its irreversible reduction. Similarly, "saving" stood for setting aside of oil wealth to enable future consumption.

- In the extended setting, proper labeling of public investment is critical. Fiscal accounting perspective would consider public investment as "spending" because it lowers the budget and current account balances and contributes to aggregate demand. However, public investment involves transforming oil revenue into an alternative form of wealth, and its analytical interpretation should be that of "saving," as in setting aside of oil wealth in the form of productive physical capital.

- Whereas the fiscal accounting interpretation is important for analyzing the shortterm fiscal stance and budget planning purposes, the analytical interpretation is more relevant for assessing intergenerational equity and long-term sustainability. When wealth is properly defined to account for both physical and financial assets, public investment is isomorphic to financial investment in wealth accounting as both represent a transformation of oil revenue into productive saving. From this perspective, the presence of public investment-while lowering the budget and current account balances - neither frontloads spending of wealth nor lowers its level; it only changes its composition. ${ }^{26}$

\footnotetext{
${ }^{26}$ A related point is the need to use proper metrics for long-term fiscal analysis. For example, the often-used non-resource primary budget balance (and fiscal rules based on this indicator) may be useful to analyze shortterm aggregate demand implications but would not adequately capture long-term issues of intergenerational equity and sustainability which require distinguishing spending of wealth (current expenditure) and saving of wealth (public investment). To this end, the non-resource primary current balance would be more relevant.
} 


\section{Concluding Thoughts}

55. This paper reconsiders the prevailing belief that, pegging expenditure to a notional return on past wealth simultaneously smooths short-term expenditure and achieves the long-term goals of intergenerational equity and sustainability. We have argued that these goals are not perfectly aligned and pursuing them requires greater prudence and better anchoring in the design of fiscal frameworks. Alongside, the paper suggests de-emphasizing expenditure smoothing and, instead, forming an explicit view about the long-term wealth target - such as the level of wealth intended for future generations - and anchoring fiscal frameworks to the path of wealth consistent with that view. Short- and medium-term policies should not lose sight of this target. The proposed prudent wealth stabilization policy provides a practical way of incorporating these considerations in policy discussions.

56. The general theme of this paper is that, in the presence of intertemporal risk, greater fiscal discipline is needed to truly pursue the goals of intergenerational equity and long-term sustainability. More research is needed to explore the paper's related and perhaps more unsettling conclusion that many countries, especially those already struggling to meet the $\mathrm{PIH}$ benchmark, are likely to be further from these goals than previously thought.

57. Future research could also explore the implications of other sources of intertemporal risk, such as the uncertain size of oil reserves and the impact of improvements in energy efficiency on long-run oil demand, as well as productivity and interest rate shocks. The latter are particularly pertinent because their impact on wealth rises with the nearing of oil exhaustion, just as the importance of oil price shocks wanes. More generally, exhaustibility of resources puts a premium on devising policies that are robust to various sources of uncertainty (see Brock and Hansen, 2018).

58. Looking ahead, attention to intergenerational considerations in economic literature is bound to grow with the rising scarcity of natural resources and continued climate change. Thus, more work (or thought) is needed toward a better concept of intergenerational equity and how to balance of our contemporaries' interests and those of future generations, who do not have a voice in these decisions.

59. The long-term considerations explored in this paper can inform other policy aspects. To this end, a holistic policy framework is needed, reflecting a balancing of short-term macroeconomic stability objectives with the goals of intergenerational equity and long-term sustainability. Commonly used fiscal rules, such as limits on non-oil primary balances, are poorly equipped to encapsulate these considerations. They require a richer modeling framework with a role for public investment and capturing key linkages between non-oil growth, oil prices, wealth, and fiscal policy. Finally, external sustainability frameworks for commodity-exporting countries that rely on the PIH suffer from the same issues highlighted in this paper. We plan to explore these issues in follow-up studies. 


\section{Appendix I. Assumptions and Calibration}

The model setting discussed in the paper was based on rough calibration for the UAE with the purpose of providing some realism to the discussion, although not necessarily the precision required for country-specific policy advice.

Oil price. The real oil price was assumed to follow an AR(1) process in logs: $\log \left(p_{t}\right)=\mu+\rho \log \left(p_{t-1}\right)+\varepsilon_{t}$, which was estimated using WEO annual oil price data (the simple average of three spot prices: Brent, West Texas Intermediate, and the Dubai Fateh, all in U.S. dollars per barrel) from 1980 to 2017 deflated by the US inflation rates (with 2017 as the base year), yielding $\mu=.5625, \rho=.8520$ and $\sigma=.2416$. These estimates imply a longterm average oil price of $\$ 49.81$ per barrel.

Oil wealth and output. The UAE's oil reserves were assumed to be 97.8 billion barrels, consistent with publicly available estimates. Oil extraction was assumed to be 3 million barrels per day, consistent with Abu Dhabi National Oil Company's (ADNOC) average output in recent years. This implies annual output $(q)$ of 1.095 billion barrels and time until resource exhaustion ( $T$ ) of 89 years. These assumptions imply an initial valuation of UAE's subsoil oil reserves (evaluated at the long-term average oil price) of $\$ 1.5$ trillion.

Financial wealth. The initial stock of financial wealth $\left(a_{0}\right)$ is assumed to be $\$ 638$ billion, reflecting average publicly available estimates of the size of UAE's largest sovereign wealth funds (ADIA and Mubadala) net of debt.

Non-oil revenue. Annual non-oil revenue $\left(y_{n}\right)$ is assumed to be $\$ 40$ billion, consistent with the number for 2017 for the consolidated general government (excluding dividend income from the sovereign wealth fund).

Total wealth. These assumptions yield an estimated initial total initial wealth $\left(w_{0}\right)$ of $\$ 3.5$ trillion.

Utility function. Each generation is assumed to derive utility from government consumption. The utility function is assumed to be: $U\left(g_{t}\right)=\frac{g_{t}^{1-\eta}}{1-\eta}$. We use $\eta=3$, corresponding to the midrange of the commonly used values for the coefficient of relative risk aversion. ${ }^{1}$

\footnotetext{
${ }^{1}$ These values are commonly used in the macro literature. The estimated coefficients in investment finance literature are typically significantly higher, while the estimates in labor and micro studies are sometimes substantially lower.
} 


\section{APPENDIX II. NON-STATIONARITY UNDER PIH: ILLUSTRATIVE EXAMPLE}

To illustrate how PIH induces non-stationarity, consider a simplified example of an economy with no non-oil revenue and initial financial assets $\left(a_{0}\right)$ of $\$ 1$ trillion. In the absence of shocks, the economy is assumed to export 1 billion barrels of oil at a price of $\$ 50 / \mathrm{barrel}$. Financial savings earn dividend income at a fixed interest rate of 3 percent. Assuming a resource horizon of 31 years yields a valuation of initial subsoil wealth $\left(Q_{0}\right)$ of $\$ 1$ trillion and total initial wealth $\left(w_{0}\right)$ of \$2 trillion.

Scenario A: Certainty. In period 1 , the present values of both subsoil and financial components of wealth are augmented by the rate of return ( $\$ 30$ billion. each), reflecting lighter discounting and dividend income respectively. At the same time, the value of extracted oil ( $\$ 50$ billion) is subtracted from subsoil wealth and added to financial savings. PIH-based consumption of 3 percent of initial wealth ( $\$ 60$ billion) ensures that the decline in subsoil wealth in period 1 is matched by the increase in financial wealth. This pattern of zero net

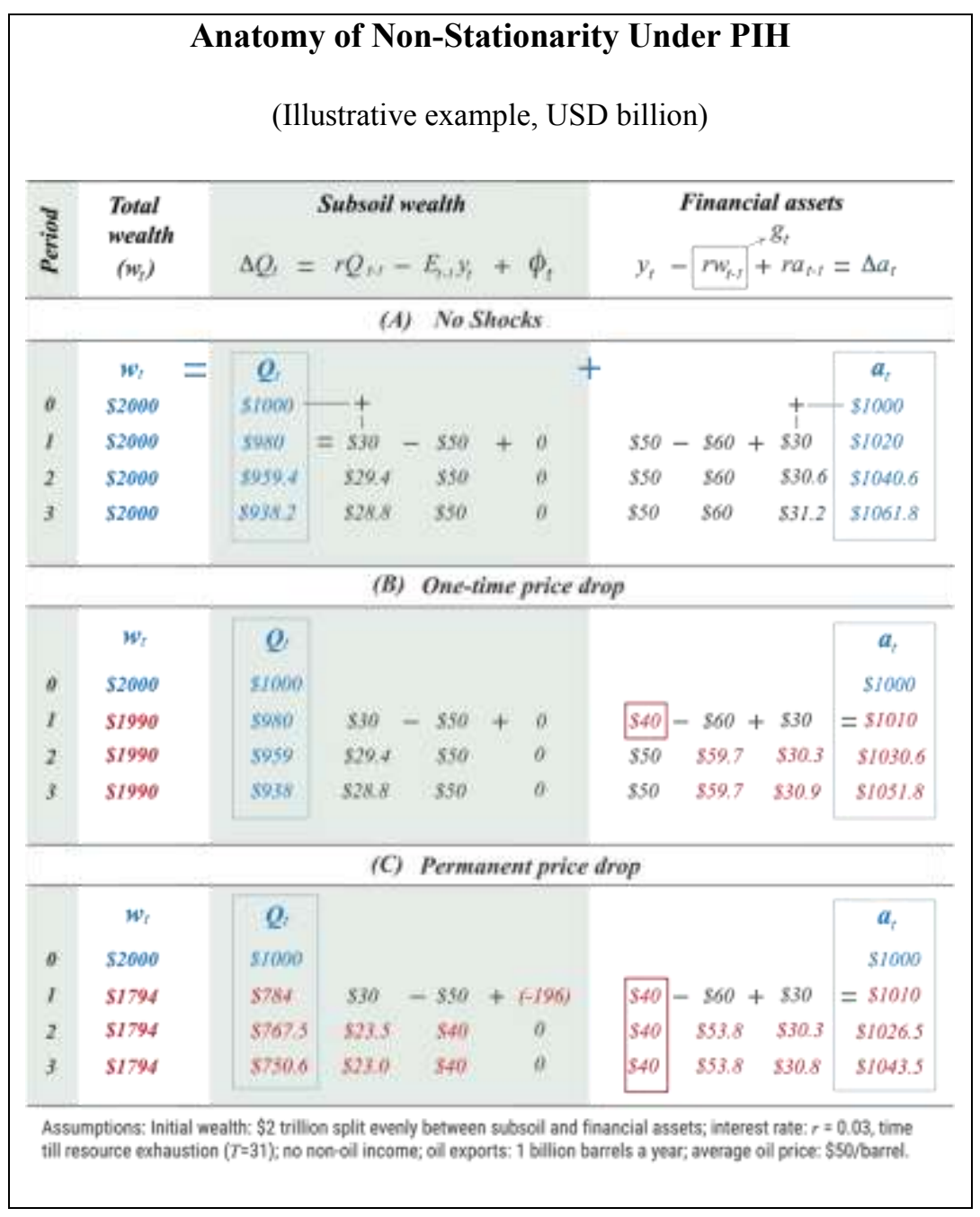
investment maintains wealth intact at $\$ 2$ trillion.

Scenario B: One-time oil price decline. Now imagine that, after oil has been extracted in the first period, its price drops to $\$ 40 /$ barrel and recovers back from period 2 on (scenario B). Initially, the resulting revenue shortfall decreases financial savings and wealth $\left(\Delta w_{t}=\Delta a_{t}=\right.$ $\Delta y_{t}=-\$ 10$ billion) relative to scenario A. In addition, this revenue shortfall would also produce a small second-round effect next period, in the form of higher/lower interest income $r \Delta a_{t}=-\$ 0.3$ billion. The adjustment of PIH-based spending to the lower level of wealth only offsets this second-round effect $\left(\Delta g_{t}=r \Delta w_{t}=-\$ 0.3\right.$ billion), leaving the memory of 
the shock's first-round impact permanently preserved in lower level of wealth, even though the oil price returns to its original level.

Scenario C: Permanent oil price decline. Finally, consider a permanent drop in the oil price. In addition to contemporaneous revenue, such a shock lowers expected oil revenue by $\$ 10$ billion in all future periods. The present value of the latter is reflected in the decreased valuation of subsoil wealth: $\Delta Q=-\sum_{i=1}^{30} \frac{10}{(1+0.03)^{i}}=-\$ 196$ billion. Total wealth, therefore, declines by $\Delta w_{t}=\Delta a_{t}+\Delta Q_{t}=-\$ 206$ billion. relative to baseline in scenario A. This valuation change is realized over time as extracted oil is sold at a lower price in each subsequent period. Each period's revenue shortfall, in turn, will produce a permanently lower interest income $(\$ 0.3)$. The combined present value of the latter $\left(\sum_{i=0}^{30} \frac{0.3}{(1+0.03)^{i}}\right)$ can be interpreted as the cumulative second-round effect from the shock. Once again, the PIH expenditure adjusts to offset this second-round effect: $\Delta g_{t}=r \Delta w_{t}=-\sum_{i=0}^{30} \frac{0.3}{(1+r)^{i}}=$ $\$ 6.2$ billion, leaving wealth permanently lower at $\$ 1,794$ billion. 


\section{Appendix III. Procedure for Optimal Policy Solution}

This Appendix describes the procedure used to obtain optimal policy rules discussed in Section IV. Since there is no uncertainty post-oil, policy rules $\left\{G_{T+i}^{*}\right\}$ for $i>0$ can be solved algebraically. In a deterministic setting (after period T), the optimal policy is $\mathrm{PIH}$ :

$$
g_{T+i}^{*}=r a_{T+i-1}
$$

We omit non-oil revenue to save space. The state variable $a_{T+i}$ evolves according to

$$
a_{T+i}=a_{T+i-1}
$$

Next, solve for policy rule $g_{T}^{*}$ at time $T$ for given policy rule $g_{T+1}^{*}$. Using the Euler Equation:

$$
u^{\prime}\left(g_{T}^{*}\right)=E_{T}\left[u^{\prime}\left(r a_{T}\right)\right]=u^{\prime}\left(r a_{T}\right)
$$

Substituting $g_{T}^{*}=r a_{T}$ into the budget constraint allows to solve for the policy rule:

$$
g_{T}^{*}=\frac{r}{1+r}\left[(1+r) a_{T-1}+q p_{T}\right]
$$

\section{Numerical solution using Endogenous Grid Method:}

1. Oil price shocks: We approximate and discretize the AR(1) oil price process, equation (4), using the method of Tauchen (1986). We use 25 grid points and let the largest shocks be 3 standard deviations from the mean. This discretization produces a transition matrix ( 25 by 25 ) and an oil price grid ( 25 by 1$)$.

2. Financial asset grid: We create a period-T financial asset $\left(a_{T-1}\right)$ grid. Its range needs to be wide enough to cover all possible outcomes given initial wealth, but also narrow enough so that the endogenous grids are bounded (they gradually should shrink in every iteration). ${ }^{1}$ We use 10,000 points to discretize the asset grid.

3. Policy Rule Iteration: For each duplet $\left(a_{T-1}^{i}, p^{j}\right)$ on the period-T asset grid and oil price grid, we can find period T's spending $G_{T}^{*}\left(a_{T-1}^{i}, p^{j}\right)$ using equation $(\mathrm{x})$. Then for each point $p^{k}$ on period T-1 oil price grid using the Euler equation

$G_{T-1}^{*}\left(a_{T-1}^{i}, p^{k}\right)=\left\{\sum_{j=1,2, . ., 25}\left[\frac{r}{1+r}\left[(1+r) a_{T-1}^{i}+p^{j} q\right]\right]^{-\eta} P\left(p_{T}=p^{j} \mid p_{T-1}=p^{k}\right)\right\}^{-1 / \eta}$

\footnotetext{
${ }^{1}$ Given our calibration, we set the period-T financial asset grid lower bound at -1.3 trillion USD, and the upper bound at 14.5 trillion USD when solving for the prudent policy. When solving for the wealth-anchoring policy, we set lower bound at -1.3 trillion USD, and upper bound at 6.3 trillion USD.
} 
Where $P\left(p_{T}=p^{j} \mid p_{T-1}=p^{k}\right)$ is the transition probability in $k$ th row and $j$ th column of the transition matrix from step 1 . Then use budget constraint, we can find

$a_{T-2}^{*}\left(a_{T-1}^{i}, p^{k}\right)=\frac{a_{T-1}^{i}-y p^{k}+\left\{\sum_{j=1,2, \ldots, 25}\left[\frac{r}{1+r}\left[(1+r) a_{T-1}^{i}+p^{j} q\right]\right]^{-\eta}{ }_{P}\left(p_{T}=p^{j} \mid p_{T-1}=p^{k}\right)\right\}^{-1 / \eta}}{1+r}$

Solve for $a_{T-2}^{*}\left(a_{T-1}^{i}, p^{k}\right)$ for each of the point on the period-T asset grid and oil price grid, then we have 25 endogenous period T-1 asset grids (one for each point on the oil price grid). With a change of variables, the solutions $G_{T-1}^{*}\left(a_{T-1}^{i}, p^{k}\right)$ can be expressed as $G_{T-1}^{*}\left(a_{T-2}^{i}, p^{k}\right)$ for each duplet $\left(a_{T-2}^{i}, p^{k}\right)$ on the endogenous period T-1 asset grid and oil price grid.

An extra step is to unify the endogenous asset grids across oil price shocks. Specifically, we remake the beginning-of-the-period asset grid at time $T-1$ with lower bound and upbound set at

$$
\begin{aligned}
& \min _{a_{T-2}^{*}}=\max _{\left\{a_{T-1}^{i}\right\}}\left(\min _{\left\{p^{k}\right\}} a_{T-2}^{*}\left(a_{T-1}^{i}, p^{k}\right)\right) \\
& \max _{a_{T-2}^{*}}=\min _{\left\{a_{T-1}^{i}\right\}}\left(\max _{\left\{p^{k}\right\}} a_{T-2}^{*}\left(a_{T-1}^{i}, p^{k}\right)\right)
\end{aligned}
$$

So we have one 1 by 10,000 equally spaced asset grid with $a_{T-2}^{1}=\min _{a_{T-2}^{*}}$ and $a_{T-2}^{10,000}=\max _{a_{T-2}^{*}}$ across all states of shocks. Then we interpolate the optimal government spending policy derived from change of variables on the new asset grid for each state of shock, yielding a 25 by 10,000 matrix: $G_{t}\left(a_{t-1}^{i}, p^{k}\right)$.

Having solved for period T-1 spending rule, $G_{T-1}^{*}\left(a_{T-2}^{i}, p^{k}\right)$, we repeat these above steps for period $\mathrm{T}-2, \mathrm{~T}-3, \ldots$, until period 1 :

$$
\begin{aligned}
& G_{t}^{*}\left(a_{t}^{i}, p^{k}\right)=\left\{\sum_{j=1,2, . .25}\left[G_{t+1}^{*}\left(a_{t}^{i}, p^{j}\right)\right]^{-\eta} P\left(p_{t+1}=p^{j} \mid p_{t}=p^{k}\right)\right\}^{-1 / \eta} \\
& a_{t-1}^{*}\left(a_{t}^{i}, p^{k}\right)=\frac{a_{t}^{i}-y p^{k}+\left\{\sum_{j=1,2, ., 25}\left[G_{t+1}^{*}\left(a_{t}^{i}, p^{j}\right)\right]^{-\eta} P\left(p_{t+1}=p^{j} \mid p_{t}=p^{k}\right)\right\}^{-1 / \eta}}{1+r}
\end{aligned}
$$

Unify the endogenous asset grids across oil price shocks:

$$
\min _{a_{t-1}^{*}}=\max _{\left\{a_{t}^{i}\right\}}\left(\min _{\left\{p^{k}\right\}} a_{t-1}^{*}\left(a_{t}^{i}, p^{k}\right)\right)
$$




$$
\max _{a_{t-1}^{*}}=\min _{\left\{a_{t}^{i}\right\}}\left(\max _{\left\{p^{k}\right\}} a_{t-1}^{*}\left(a_{t}^{i}, p^{k}\right)\right)
$$

So we have a one 1 by 10,000 equally spaced asset grid with $a_{t-1}^{1}=\min _{a_{t-1}^{*}}$ and $a_{t-1}^{10,000}=\max _{a_{t-1}^{*}}$ across all states of shocks. Then we interpolate the optimal government spending policy solved above on this asset grid, yielding a 25 by 10,000 matrix:

$G_{t}\left(a_{t-1}^{i}, p^{k}\right)$.

A final check is to ensure that the calibrated initial asset lies on the period 1 asset grid. 


\section{Appendix IV. A Setting With Public InVestment}

This Appendix examines the implication of introducing productive public investment into the basic setting of Section II. Specifically, let us assume that non-oil output in equation (3) is endogenous and, at least partially, determined by public capital $k_{t-1}$ :

$$
y_{t}^{n}=A k_{t-1}^{\eta}, \eta \in(0,1)
$$

where $A$ is a scale parameter capturing various other determinants which are assumed fixed (e.g. labor and private capital). In turn, public capital is subject to a depreciation rate $(\delta)$ and is accumulated via public investment $I_{t}$ :

$$
k_{t}=(1-\delta) k_{t-1}+I_{t}
$$

Financial capital in equation (2) must now be changed to reflect public investment:

$$
a_{t}=(1+r) a_{t-1}+y_{t}+y_{t}^{n}-g_{t}-I_{t}
$$

The evolution of oil wealth in equation (8) is unchanged:

$$
Q_{t}=(1+r) Q_{t-1}-E_{t-1} y_{t}+\phi_{t}
$$

Total wealth $\left(w_{t}\right)$ must now be redefined as the sum of financial and physical capital as well as the underground oil wealth: $w_{t}=k_{t}+a_{t}+Q_{t}$. Combining the last three equations results in the following law of motion for total wealth:

$$
w_{t}=(1+r) w_{t-1}-(r+\delta) k_{t-1}+A k_{t-1}^{\eta}-g_{t}+\widetilde{\phi_{t}}
$$

The two additional terms compared to equation (9) reflect the gross return on public capital (non-oil output) as well as the opportunity cost of capital, i.e. interest rate plus depreciation. Maximizing the objective function (10) subject to this constraint yields familiar optimality conditions:

$$
\begin{gathered}
U^{\prime}\left(g_{t}\right)=\beta(1+r) E_{t} U^{\prime}\left(g_{t+1}\right) \\
\eta A k_{t}^{\eta-1}=r+\delta
\end{gathered}
$$

The first equation is identical to (11) while the second equation states that the optimal level of public capital must equate its marginal product with its opportunity cost. Note, that if the oil price is the only source of uncertainty, the optimal level of capital is constant $\left(k_{t}=k, \forall t\right)$ and is independent of the oil price. Furthermore, making use of the last equation, the law of motion for wealth can be re-written as follows:

$$
w_{t}=(1+r) w_{t-1}+(r+\delta) \frac{1-\eta}{\eta} k-g_{t}+\widetilde{\phi_{t}}
$$


The second term on the right-hand side of this equation should be interpreted as the difference in the average rates of return on various components of total wealth which arises with the introduction of a concave production function. While the NPV of both financial and underground wealth continue to grow at the rate of $r$, the average rate of return on capital $\left(\frac{y^{n}}{k}=\frac{r+\delta}{\eta}\right)$ is higher than its marginal rate of return $(r+\delta)$. The excess of this return (less depreciation) over the average return on other components of wealth is captured by the additional term that was not present in equation (9).

The result of a broader range of available investment options implies that some of the oil wealth is converted into physical, rather than financial, capital. As discussed above, total wealth now includes physical capital, and the long-term return on wealth also includes the (higher) average return on capital. Therefore, the PIH benchmark-a policy that maintains wealth constant in the absence of uncertainty $\left(\widetilde{\phi_{t}}=0\right)$ - must be revised to account for this excess return relative to the base model:

$$
g_{t}=r w_{t-1}+(r+\delta) \frac{1-\eta}{\eta} k
$$

Finally, combining the last two equations, it is easy to see that wealth continues to follow a random walk: $w_{t}=w_{t-1}+\widetilde{\phi_{t}}$ unless all oil savings are invested in physical capital as in Hartwick's framework. 


\section{REFERENCES}

Araujo, Juliana, Grace Li, Marcos Poplawski Ribeiro, and Luis-Felipe Zanna, 2016, "Current account norms in natural resource rich and capital scarce economies," Journal of Development Economics, Vol. 120 (May 2016), pp. 144-156

Arrow, Kenneth, 1973, "Rawls's Principle of Just Saving," The Swedish Journal of Economics, Vol. 75, No. 4, pp. 323-335.

Barnett, Steven and Rolando Ossowski, 2002, "Operational Aspects of Fiscal Policy in OilProducing Countries,” IMF Working Paper No. WP/02/177 (Washington: International Monetary Fund).

Bems, Rudolfs and Irene Carvalho, 2011, "The current account and precautionary savings for exporters of exhaustible resources," Journal of International Economics, Vol. 84, pp. 48-64.

Berg, Andrew, Rafael Portillo, Shu-Chun S. Yang, and Luis-Felipe Zanna, 2012, "Public Investment in Resource-Abundant Developing Countries," IMF Working Paper No. WP/12/274 (Washington: International Monetary Fund).

Blanchard, Olivier J. and Mitali Das, 2017, “A New Index of Debt Sustainability,” NBER Working Paper \#24068 (November 2017).

Brock, William, and Lars P. Hansen, 2018, "Wrestling with Uncertainty in Climate Economic Models," mimeo.

Davis, Jeffrey, Rolando Ossowski, and Annalisa Fedelino, eds., 2012, Fiscal Policy Formulation and Implementation in Oil-Producing Countries, (Washington: International Monetary Fund).

Engel, Ricardo and Rodrigo Valdes, 2000, “Optimal Fiscal Strategy for Oil Exporting Countries,” IMF Working Paper No. WP/00/118 (Washington: International Monetary Fund).

Friedman, Milton, 1957, "The Permanent Income Hypothesis," Chapter III in A Theory of the Consumption Function, (Princeton University Press).

Ghironi, Fabio, 2006, "Macroeconomic Interdependence under Incomplete Markets," Journal of International Economics, Vol. 70 (2), December 2006, pp. 428-450.

Ghironi, Fabio, 2008, “The Role of Net Foreign Assets in a New Keynesian Small Open Economy Model," Journal of International Economics, Vol. 70 (2), December 2006, pp. 428-450. 
Hartwick, John, 1977, "Intergenerational Equity and the Investing of Rents from Exhaustible Resources," American Economic Review, Vol. 66, pp. 972-4.

Hartwick, John, 1978a, "Substitution Among Exhaustible Resources and Intergenerational Equity," Review of Economic Studies, Vol. 45, pp. 347-54.

Hartwick, John, 1978b, "Investing Returns from Depleting Renewable Resource Stocks and Intergenerational Equity," Economic Letters, Vol. 1, pp. 85-88.

Hotelling, Harold, 1931, "The Economics of Exhaustible Resources," Journal of Political Economy, Vol. 39 (2), pp. 137-175.

International Monetary Fund, 2012, "Macroeconomic Policy Frameworks for Resource-Rich Developing Countries," IMF Staff Paper (Washington: International Monetary Fund). https://www.imf.org/en/Publications/Policy-Papers/Issues/2016/12/31/MacroeconomicPolicy-Frameworks-for-Resource-Rich-Developing-Countries-PP4698

, 2012a, "Macroeconomic Policy Frameworks for Resource-Rich Developing Countries - Analytic Frameworks and Applications - Supplement 1," IMF Staff Paper (Washington: International Monetary Fund).

, 2012b, "Macroeconomic Policy Frameworks for Resource-Rich Developing Countries-Analytic Frameworks and Applications - Supplement 2," IMF Staff Paper (Washington: International Monetary Fund).

, 2013, Regional Economic Outlook: Middle East and Central Asia,

(Washington: International Monetary Fund).

https://www.imf.org/en/Publications/REO/MECA/Issues/2017/01/07/Regional-Economic-

Outlook-Middle-East-and-Central-Asia6

, 2015, “The Commodities Roller Coaster: A Fiscal Framework for Uncertain

Times," Fiscal Monitor, October 2015, World Economic and Financial Surveys series (Washington: International Monetary Fund).

Kimball, Miles, 1990, "Precautionary Saving in the Small and in the Large," Econometrica, Vol. 58(1), pp. 53-73.

Kumhof, Michael, Douglas Laxton, Dirk Muir, and Susana Mursula, 2010, "The Global Integrated Monetary and Fiscal Model (GIMF)—Theoretical Structure," IMF Working Paper No. WP/10/34 (Washington: International Monetary Fund).

Koopmans, Tjalling, 1973, "Some Observations on "Optimal" Economic Growth and Exhaustible Resources," Cowles Foundation Discussion Paper No. 356, Yale University. 
Koopmans, Tjalling, 1974, "Proof for a Case when Discounting Advances the Doomsday," The Review of Economic Studies, Vol. 41, pp. 117-120.

Leland, Hayne E., 1968, "Saving and Uncertainty: The Precautionary Demand for Saving," Quarterly Journal of Economics, 82, pp. 465-473.

Obstfeld, Maurice, and Kenneth Rogoff, 2005, "Exchange Rate Dynamics Redux," Journal of Political Economy, Vol. 103 (3), pp. 624-660.

Obstfeld, Maurice, 1982, "Aggregate Spending and the Terms of Trade: Is There a LaursenMetzler effect?," Quarterly Journal of Economics, 97, pp. 251-270.

Ossowski, Rolando, and Havard Halland, 2016, "Fiscal Management in Resource-Rich Countries," World Bank Study (Washington: The World Bank).

Pratt, John W., 1964, “Risk Aversion in the Small and Large,” Econometrica, 32, pp. 111136.

Ramsey, Frank, 1928, “A Mathematical Theory of Saving,” The Economic Journal, Vol. 38, No. 152, pp. 543-559.

Rawls, John, 1971, A Theory of Justice (Harvard University Press, Cambridge, 1971).

Schmitt-Grohe, Stephanie and Martin Uribe, 2003, "Closing Small Open Economy Models," Journal of International Economics, Vol 61(1), October 2003, pp. 163-185.

Solow, Robert, 1974, "Intergenerational Equity and Exhaustible Resources," The Review of Economic Studies, Vol. 41, pp. 29-45.

Solow, Robert, 1986, "On the Intergenerational Allocation of Natural Resources," The Scandinavian Journal of Economics, Vol. 88, No. 1, pp. 141-149

Tauchen, George, 1986, "Finite State Markov-chain Approximations to Univariate and Vector Autoregressions," Economic Letters, Vol. 20(2), pp. 177-181.

Uzawa, Hirofumi, 1968, "Time preference, the consumption function, and optimum asset holdings," in: J.N. Wolfe, ed., Capital and growth: Papers in honor of Sir John Hicks (Aldine, Chicago, IL).

van der Ploeg, Rick, 2014, "Guidelines for Exploiting Natural Resource Wealth," Oxford Review of Economic Policy, Volume 30 (1), pp. 145-169.

van der Ploeg, Rick, 2016, "Macro Policy Responses to Natural Resource Windfalls and the Crash in Commodity Prices," OxCarre Working Papers 178, Oxford Centre for the Analysis of Resource Rich Economies, University of Oxford. 